\title{
Interactions between immunity, proliferation and molecular subtype in breast cancer prognosis
}

\author{
Srikanth Nagalla', Jeff W Chou², Mark C Willingham³ ${ }^{3}$ Jimmy Ruiz ${ }^{1}$, James P Vaughn ${ }^{4}$, Purnima Dubey ${ }^{3}$, \\ Timothy L Lash ${ }^{5,6}$, Stephen J Hamilton-Dutoit ${ }^{7}$, Jonas Bergh ${ }^{8,9}$, Christos Sotiriou ${ }^{10}$, Michael A Black ${ }^{11}$ and \\ Lance D Miller ${ }^{4^{*}}$
}

\begin{abstract}
Background: Gene expression signatures indicative of tumor proliferative capacity and tumor-immune cell interactions have emerged as principal biology-driven predictors of breast cancer outcomes. How these signatures relate to one another in biological and prognostic contexts remains to be clarified.

Results: To investigate the relationship between proliferation and immune gene signatures, we analyzed an integrated dataset of 1,954 clinically annotated breast tumor expression profiles randomized into training and test sets to allow two-way discovery and validation of gene-survival associations. Hierarchical clustering revealed a large cluster of distant metastasis-free survival-associated genes with known immunological functions that further partitioned into three distinct immune metagenes likely reflecting B cells and/or plasma cells; T cells and natural killer cells; and monocytes and/or dendritic cells. A proliferation metagene allowed stratification of cases into proliferation tertiles. The prognostic strength of these metagenes was largely restricted to tumors within the highest proliferation tertile, though intrinsic subtype-specific differences were observed in the intermediate and low proliferation tertiles. In highly proliferative tumors, high tertile immune metagene expression equated with markedly reduced risk of metastasis whereas tumors with low tertile expression of any one of the three immune metagenes were associated with poor outcome despite higher expression of the other two metagenes.
\end{abstract}

Conclusions: These findings suggest that a productive interplay among multiple immune cell types at the tumor site promotes long-term anti-metastatic immunity in a proliferation-dependent manner. The emergence of a subset of effective immune responders among highly proliferative tumors has novel prognostic ramifications.

Keywords: Breast cancer, gene signatures, hierarchical clustering, immune metagene, intrinsic subtypes, metagene tertiles, multivariable analysis, prognosis, proliferation metagene, survival analysis

\section{Background}

Expression profiling studies in human tumors have enabled new insights into the genes and pathways that contribute to tumorigenesis and spurred the development of gene expression signatures prognostic of patient outcomes. Genes comprising prognostic signatures often provide clues to the pathobiological mechanisms that drive cancer progression. With the aim of discovering genes with statistical associations with breast cancer recurrence, we and others have identified a number of

\footnotetext{
* Correspondence: Idmiller@wakehealth.edu

${ }^{4}$ Department of Cancer Biology, Wake Forest School of Medicine, Medical

Center Boulevard, Winston-Salem, NC, 27157, USA

Full list of author information is available at the end of the article
}

genes with roles in cellular proliferation [1-6], including multi-gene proliferation signatures that directly reflect tumor proliferative capacity [1,4-7]. These signatures are highly significantly associated with poor patient outcomes, consistent with the view that uncontrolled cell proliferation is a central feature of neoplastic disease and, ultimately, a contributing factor in metastatic progression [8,9]. Indeed, proliferation-associated genes are common components of many previously reported prognostic gene signatures, including Genomic Health's 21gene Oncotype Dx test $[10,11]$ (Genomic Health, Inc., Redwood City, CA, USA), and frequently account for the majority of the prognostic power driving the performance of these signatures [12-14]. Thus, a clear

\section{Biomed Central}


biological understanding of how prognostic genes relate to different aspects of tumor pathobiology is imperative to both the optimal construction of prognostic models and the elucidation of key regulators of cancer behavior.

In recent years, we and others have observed that elevated expression levels of many genes involved in immune response pathways are associated with reduced risk of breast cancer recurrence [15-19]. These observations support the view that cancer-leukocyte interactions in the microenvironment of established tumors may function to limit the growth and metastatic progression of breast cancer [20-22]. However, the extent to which these genes reflect different effector cell populations, or contribute to patient prognosis in the presence of other predictive biomarkers such as proliferation, remains unclear.

In this report, we investigate the biological origins of coordinately expressed genes in breast cancer that exhibit statistical associations with patient distant metastasis-free survival (DMFS). We identify gene clusters indicative of tumor-immune cell interactions that organize into three distinct immunity-related gene signatures, or metagenes, and shed light on their prognostic implications for tumors of differing proliferative capacity with an emphasis on highly proliferative breast cancers and the most aggressive intrinsic molecular subtypes in particular.

\section{Results}

Reproducible clustering of prognostic genes with immune cell functions

To characterize prognostic gene modules, we created a multi-study microarray database of 2,116 breast tumor expression profiles of which 1,954 were annotated with corresponding clinicopathological data including DMFS (See Additional file 1 for clinical details). To facilitate gene discovery, we randomized the dataset across study groups and clinical features into two equivalent patient subpopulations, termed patient groups 977A and 977B (Table 1). In each patient group, Cox proportional hazards regression was conducted to identify genes with statistically significant associations with DMFS while controlling for false discoveries $(\mathrm{q}<0.1)$. The analysis identified 3,094 significant gene probe sets in 977A and 3,304 in 977B (gene details provided in Additional file 2). In parallel, the DMFS-associated genes identified in each patient group were hierarchically clustered to enable analysis of gene correlation structure (Figure 1 and Additional file 3). As anticipated, a proliferation gene cluster was readily identifiable in both patient groups. This cluster of genes has been previously described in multiple studies as being significantly associated with patient survival $[1,2,5,23]$, and consists of the highly correlated group of cell cycle genes associated
Table 1 Clinical characteristics of the randomized patient groups

\begin{tabular}{lrrr}
\hline Characteristic & $977 \mathrm{~A}$ & $977 \mathrm{~B}$ \\
& Number & $\%$ & Number
\end{tabular}

Age at diagnosis (years)

$\leq 40$

$41-50$

$>50$

unknown

Distant metastasis-free survival (years)

no recurrence $<5$

recurrence, $<5$

lost to follow-up, $<5$

no recurrence, 5-to 10

recurrence, 5 to 10

lost to follow-up, 5 to 10

Estrogen receptor status

positive

negative

unknown

Lymph node status

negative

positive

unknown

Histologic grade

well differentiated

moderately differentiated

poorly differentiated

unknown

Tumor size $(\mathrm{cm})$

$\leq 2.0$

2.1 to 5.0

$>5.0$

unknown

Adjuvant treatment

yes

no

tamoxifen monotherapy (ER+)

chemotherapy

unknown

Molecular subtypes

Basal

HER2-E

Claudin-Low

Luminal A

Luminal B

$\begin{array}{cccc}89 & 9 & 80 & 8 \\ 197 & 20 & 207 & 21 \\ 494 & 51 & 492 & 50 \\ 197 & 20 & 198 & 20\end{array}$

$617 \quad 63 \quad 648 \quad 66$

$\begin{array}{llll}198 & 20 & 184 & 19\end{array}$

$\begin{array}{llll}111 & 11 \quad 96 \quad 10\end{array}$

$\begin{array}{llll}245 & 25 & 253 & 26\end{array}$

$\begin{array}{llll}51 & 5 & 49 & 5\end{array}$

$\begin{array}{llll}357 & 37 & 395 & 40\end{array}$

$657 \quad 67 \quad 686 \quad 70$

$\begin{array}{llll}220 & 23 & 181 & 19\end{array}$

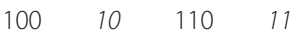

$\begin{array}{llll}749 & 77 & 749 & 77\end{array}$

$\begin{array}{llll}217 & 22 & 220 & 23\end{array}$

$\begin{array}{llll}11 & 1 & 8 & 1\end{array}$

$\begin{array}{llll}105 & 11 & 131 & 13\end{array}$

$\begin{array}{llll}317 & 31 & 335 & 34\end{array}$

$\begin{array}{llll}316 & 32 & 260 & 27\end{array}$

$\begin{array}{llll}239 & 24 & 251 & 26\end{array}$

$\begin{array}{llll}482 & 49 \quad 505 \quad 52\end{array}$

$\begin{array}{llll}363 & 37 & 356 & 36\end{array}$

$\begin{array}{llll}29 & 3 & 19 & 2\end{array}$

$\begin{array}{llll}103 & 11 & 97 & 10\end{array}$

$\begin{array}{llll}478 & 49 & 488 & 50\end{array}$

$\begin{array}{llll}490 & 50 & 484 & 50\end{array}$

$\begin{array}{llll}318 & 33 & 332 & 34\end{array}$

$\begin{array}{llll}141 & 14 & 140 & 14\end{array}$

$\begin{array}{llll}9 & 1 & 5 & 1\end{array}$

ER+: Estrogen receptor-positive breast cancer; HER2-E: human epidermal growth factor receptor 2-enriched.

with markers of tumor cell proliferation $[6,7,24]$. In a subset analysis, we examined the correlation between this proliferation gene cluster and clinical markers of proliferation. As expected, we observed a strong positive correlation between the average expression of the genes 


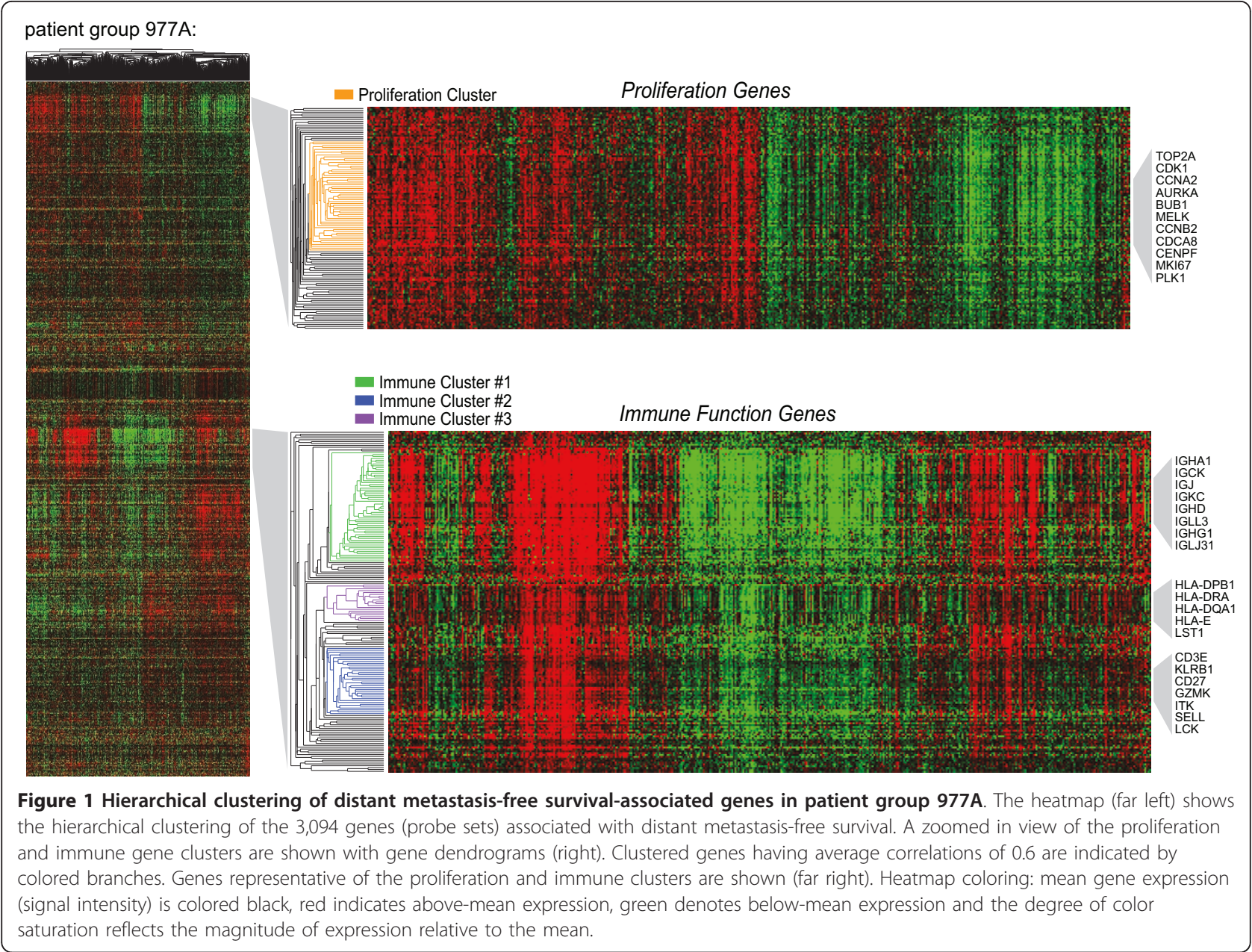

comprising this cluster and Ki67 staining (by MIB1 antibody) and mitotic index (Additional file 4), consistent with the notion that these genes quantify tumor proliferative capacity $[6,25]$.

Further inspection of the cluster architecture revealed a large reproducible cluster of genes associated with immune cell functions that exhibited negligible correlation with the proliferation cluster (Figure 1 and Additional file 3). Gene ontology (GO) enrichment analysis of the genes within this large cluster showed highly significant enrichment for numerous immune cell processes including lymphocyte activation, antigen processing and presentation, positive regulation of immune system process, and other annotations specific for different immune cell lineages $(P<0.0001$, false discovery rate (FDR)-adjusted; Additional file 5). Closer inspection of the nested correlation structure revealed distinct gene 'subclusters' that were highly reproducible between patient groups (Figure 1 and Additional file 3). While one predominant proliferation cluster emerged, three distinct immune gene subclusters (termed immune subclusters \#1, \#2 and \#3) could be discerned in both 977A and 977B. To investigate the underlying biology associated with these subclusters, genes comprising each subcluster were selected from the dendrogram branches using a threshold of average Pearson correlation of 0.6 (see Methods). The number of gene probe sets per subcluster ranged from 20 to 59, and details regarding their subcluster membership are shown in Additional file 6 . Although the genes comprising the subclusters were independently selected from 977A and 977B (based on correlation structure alone), we observed a high degree of probe overlap when comparing subclusters across the two groups (Additional file 7A). The majority of probes identified within a cluster of one patient group were also found within the cognate cluster of the other patient group, though three genes were observed to exhibit cluster inconsistency (associated with immune subcluster \#2 in one patient group and immune subcluster \#3 in the other). For a more decisive comparison of the expression patterns of the cognate clusters, we examined the correlation between cognate clusters of 
977A and 977B. We observed near perfect correlations between cognate clusters with Pearson correlation coefficients (r) ranging from 0.97 to 0.99 (Additional file 7B). For the immune subclusters, this indicated that the hierarchical organization of the genes into three discernible expression vectors was a reproducible event.

\section{Immune gene subclusters exhibit leukocyte cell type- specific expression}

We hypothesized that the immune gene subclusters likely reflect the relative abundance of tumor-infiltrating immune cells. We employed several strategies to investigate this hypothesis. First, we investigated the expression patterns of the immune cluster genes in the microarray dataset of Abbas and colleagues, comprising a comprehensive collection of human leukocyte gene expression profiles [26]. Strikingly, the nested correlation structure and gene composition of the immune gene subclusters, as observed in the breast tumors, remained largely unaltered in this pan-leukocyte dataset after hierarchical clustering (Figure 2; also see Additional file 8 for greater detail). Consistent with our hypothesis, we found that immune cluster \#1 consisted of genes (mostly immunoglobulin-encoding genes) highly and exclusively expressed in B cell/plasma cell populations (hence termed the $\mathrm{B} / \mathrm{P}$ Cluster). By contrast, expression of genes in immune cluster \#2 (such as components of the $\mathrm{T}$ cell receptor-CD3 complex and granzymes) were found to be mostly restricted to $\mathrm{T}$ cells and natural killer cells (hence termed the T/NK Cluster), whereas the genes of immune cluster \#3 (including major histocompatibility complex (MHC) class II (human leukocyte antigen; HLA) and myeloid-specific markers (for example, colony stimulating factor 1 receptor)) were most consistently expressed at highest levels in monocytes and dendritic cells (hence termed the M/D Cluster).

Next, we examined the immune gene subclusters for gene-level enrichment of GO terms [27]. Numerous highly significant biological annotations emerged that were consistent with our observations in the Abbas leukocyte dataset. Representative GO terms selected from among the top 10 most significant terms for each subcluster are shown in Table 2 . The $\mathrm{B} / \mathrm{P}$ cluster was highly enriched for variable region immunoglobulin genes involved in antigen binding - consistent with B cell/ plasma cell biology. The T/NK cluster was enriched for terms consistent with the positive regulation of lymphocyte activation and differentiation, $\mathrm{T}$ cell signaling and natural killer cell functions. The M/D cluster was enriched for significant terms associated with MHC class II-mediated antigen processing and presentation characteristic of macrophages and dendritic cells.

We then tested for direct associations between the magnitude of expression of the immune gene subclusters and the relative abundance of tumor-infiltrating leukocytes. To reduce dimensionality of the gene expression data, we averaged the gene signal intensities within each gene subcluster according to the method of Dave and colleagues [28] to generate a 'metagene' expression value for each breast cancer case. The immune metagene values were then compared to measurements of immune cell infiltrate assessed in tumor sections $(n=35)$ at another institution [29]. Significant positive trends between metagene values and immune cell abundance were observed for each metagene $(\mathrm{B} / \mathrm{P}, P=0.08 ; \mathrm{T} / \mathrm{NK}, P=0.02 ; \mathrm{M} / \mathrm{D}, P$ $=0.009$; Additional file 9A). Additionally, we extrapolated the immune metagene concept to a more quantitative RNA analysis platform to investigate how the concept might be generalized to a diagnostic setting. Genes representative of the $\mathrm{B} / \mathrm{P}$ and $\mathrm{T} / \mathrm{NK}$ metagenes were profiled prospectively in a panel of estrogen receptor-positive $(E R+)$, formalin-fixed paraffinembedded (FFPE) breast tumor sections using the Panomics QuantiGene Plex 2.0 RNA assay system (Affymetrix, Santa Clara, CA, USA). Expression levels of the selected genes were found to be positively and significantly correlated with total leukocyte counts (B/ $\mathrm{P}, P=0.005$; T/NK, $P=0.02$; Additional file $9 \mathrm{~B}-\mathrm{D}$ ). Taken together, these findings support the view that the immune gene subclusters reflect the relative abundance of infiltrating immune cell populations.

\section{Immune metagenes risk stratify tumors with high proliferation rates}

We examined the prognostic relationships between the proliferation and immune metagenes. First, the metagene expression values were used to divide breast cancer cases into population tertiles. This procedure is illustrated in Figure 3 where patient group 977A is shown divided into proliferation metagene tertiles then further stratified into low $\left(\mathrm{P}^{\mathrm{L}}\right)$, intermediate $\left(\mathrm{P}^{\mathrm{I}}\right)$, and high $\left(\mathrm{P}^{\mathrm{H}}\right)$ expression tertiles by the $\mathrm{B} / \mathrm{P}$ metagene. Kaplan-Meier plots of the DMFS of patients classified by the B/P tertiles are shown. Strikingly, we found that the prognostic power of the $\mathrm{B} / \mathrm{P}$ metagene, while distinct from that of proliferation, is dependent on the proliferative status of the tumor. Specifically, we observed that its prognostic power resides exclusively in the highly proliferative tumors, as defined by the upper proliferation metagene tertile (Figure 3E). To investigate the robustness of this phenomenon and to reduce the potential for data overfitting, we used each patient group (977A and 977B) in both training and testing scenarios. For example, using group 977A as a training set, the gene content of the proliferation and the immune metagenes were defined and their corresponding expression tertile cut-points were determined. These metagenes and tertile cut-points 


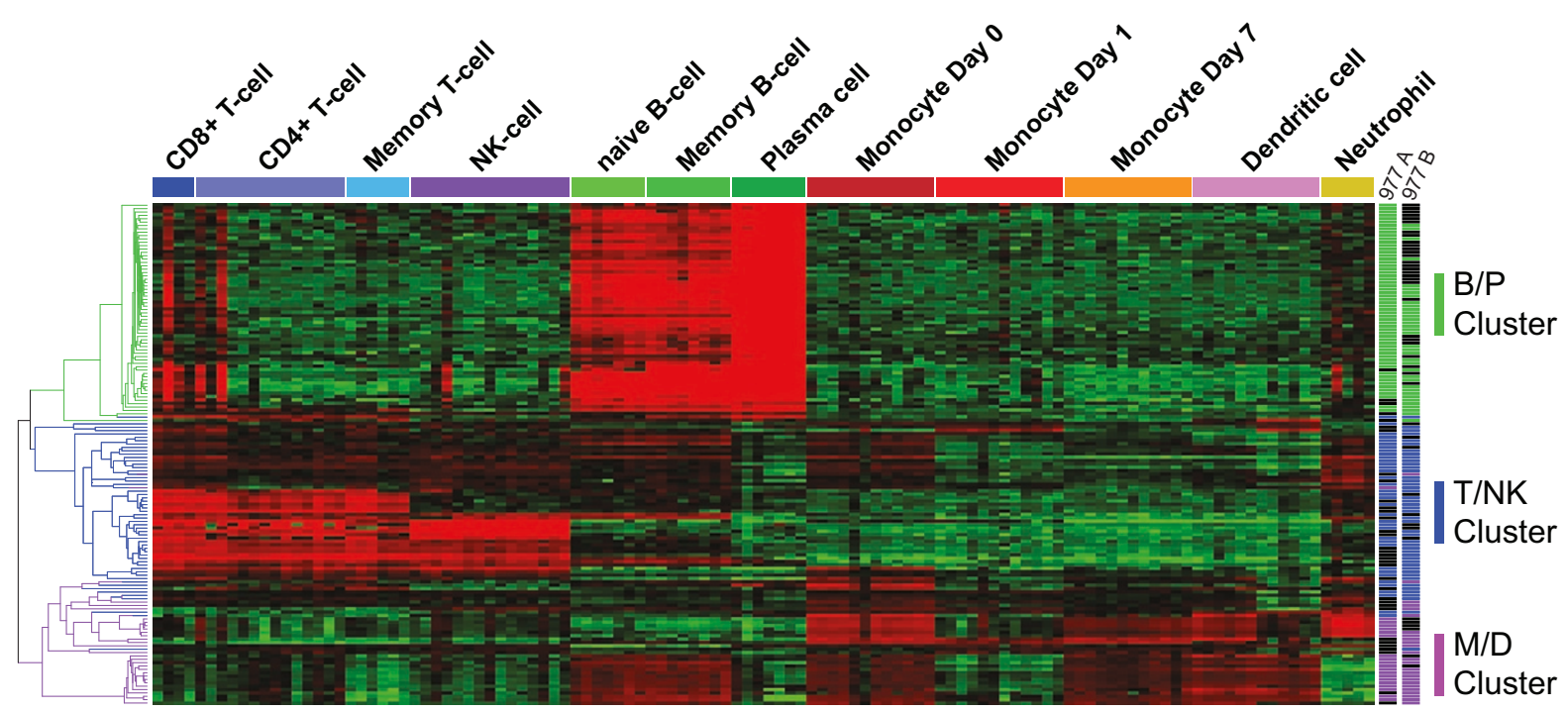

Figure 2 Breast tumor-derived immune gene clusters differentiate specific leukocyte cell types. The breast tumor-derived immune gene clusters were analyzed in the pan-leukocyte expression dataset of Abbas et al. [26]. Signal intensities of the probe sets comprising the tumorimmune metagenes were extracted by probe set ID from the normalized leukocyte expression profiles of the Abbas dataset and hierarchically clustered by Pearson correlation and average linkage clustering. Genes belonging to the three immune clusters identified in groups $977 \mathrm{~A}$ and 977B are indicated by color (green: B/P Cluster; blue: T/NK Cluster; magenta: M/D Cluster) in the gene dendrogram (left) and to the right of the figure. Clustered array profiles are delineated by horizontal colored bars (at top of figure) and named according to immune cell type. Array experimental annotations are provided in Additional file 8. B/P: B cell/plasma cells; M/D: monocytes and dendritic cells; NK; natural killer; T/NK: T cell and natural killer cells.

were used to group 977B cases into low, intermediate and high expression tertiles for survival analysis. Shown in Figure 4 are the cross-group test results for each of the immune metagenes. Consistently, we observed that all three immune metagenes displayed a highly significant positive association with DMFS that is conditionally prognostic - dependent on the high proliferation phenotype defined by the upper tertile of the proliferation metagene (the $\mathrm{P}^{\mathrm{H}}$ tertile).

\section{Immune metagenes have non-redundant associations} with metastatic recurrence

Although the immune metagenes form distinct gene subclusters, their expression profiles are intrinsically

Table 2 Gene Ontology enrichment analysis of immune cluster genes.

\begin{tabular}{|c|c|c|c|c|}
\hline & Gene Ontology term & $\%^{1}$ & Univariate $P$-value ${ }^{2}$ & FDR-adjusted $P$-value ${ }^{3}$ \\
\hline \multirow[t]{5}{*}{ B/P Cluster } & Immunoglobulin & 34.5 & $4.6 \mathrm{E}-25$ & $1.8 \mathrm{E}-23$ \\
\hline & Immunoglobulin V-set & 37.9 & 2.6E-18 & $2.5 \mathrm{E}-17$ \\
\hline & Antigen binding & 27.6 & 8.7E-16 & $1.2 \mathrm{E}-14$ \\
\hline & Immunoglobulin-like fold & 44.8 & $9.7 \mathrm{E}-16$ & $4.8 \mathrm{E}-15$ \\
\hline & Immune response & 41.4 & $2.0 \mathrm{E}-13$ & $2.6 \mathrm{E}-11$ \\
\hline \multirow{5}{*}{$\begin{array}{c}\text { T/NK } \\
\text { Cluster }\end{array}$} & Positive regulation of immune system process & 24.4 & 1.7E-08 & 2.5E-05 \\
\hline & Natural killer cell mediated cytotoxicity & 19.5 & 9.7E-07 & $5.9 \mathrm{E}-05$ \\
\hline & Positive regulation of lymphocyte activation & 17.1 & 3.3E-07 & $6.9 \mathrm{E}-05$ \\
\hline & $\mathrm{T}$ cell & 12.2 & $1.3 \mathrm{E}-06$ & $7.2 \mathrm{E}-05$ \\
\hline & Positive regulation of lymphocyte differentiation & 12.2 & 3.7E-06 & 3.3E-04 \\
\hline \multirow[t]{5}{*}{ M/D Cluster } & MHC class II, alpha/beta chain, N-terminal & 39.1 & 7.0E-22 & $3.4 \mathrm{E}-20$ \\
\hline & Class II histocompatibility antigen & 39.1 & $1.3 \mathrm{E}-19$ & $1.9 \mathrm{E}-18$ \\
\hline & MHC class II protein complex & 39.1 & 4.6E-20 & 3.3E-18 \\
\hline & Immunoglobulin C1-set & 43.5 & 7.0E-18 & 1.7E-16 \\
\hline & Antigen processing and presentation & 47.8 & $1.3 \mathrm{E}-18$ & $3.0 \mathrm{E}-16$ \\
\hline
\end{tabular}

${ }^{1}$ percentage of cluster genes (relative to all genes on array) annotated for a given ontology term; ${ }^{2}$ modified Fisher's Exact Test; ${ }^{3}$ Benjamini and Hochberg false discovery rate-adjusted $P$-value. B/P: B cell/plasma cell cluster; M/D: monocytes and dendritic cell cluster; T/NK: T cell and natural killer cell cluster. 

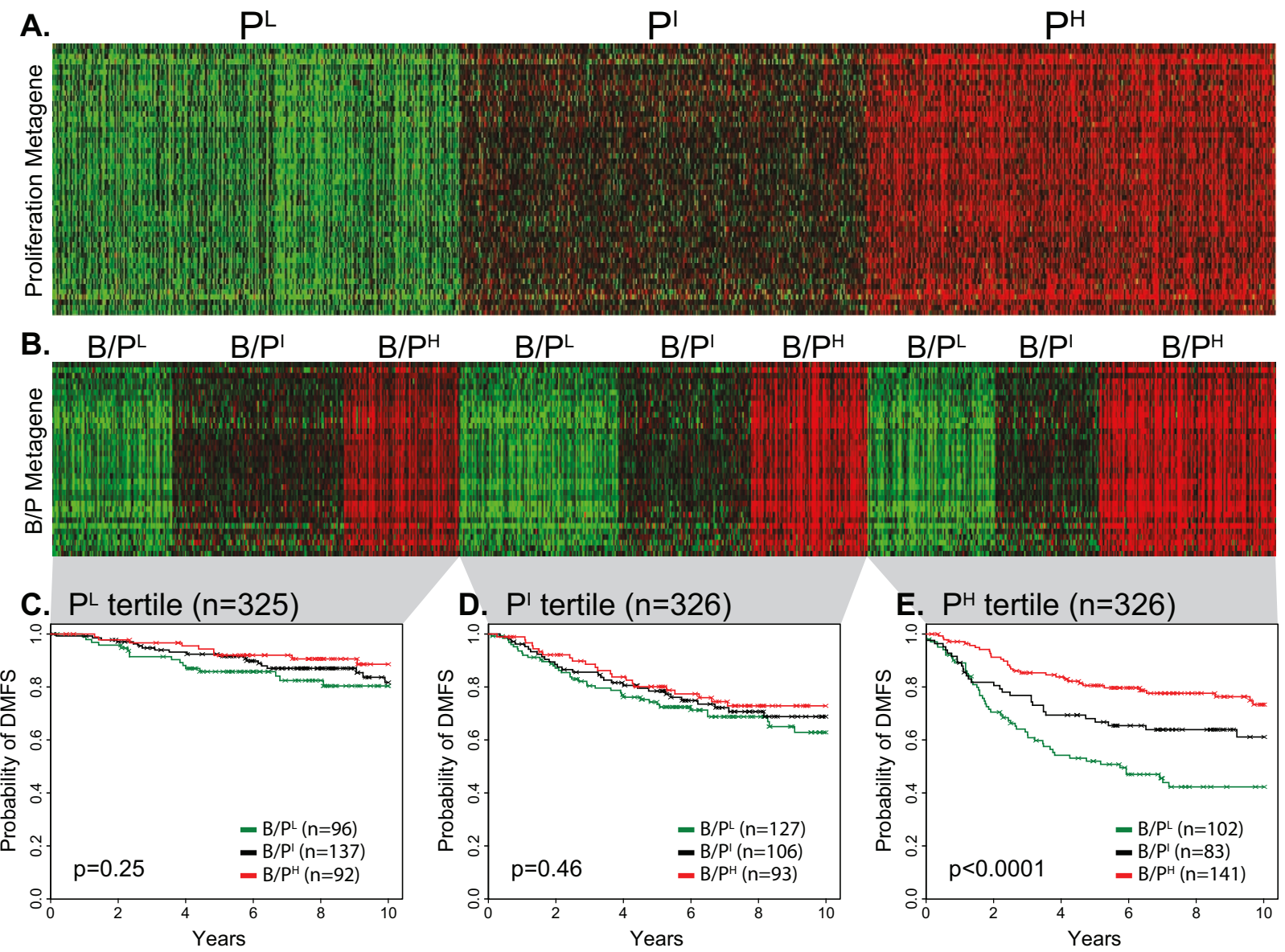

Figure 3 Prognostic stratification of highly proliferative tumors by the B/P metagene. The (A) proliferation metagene and (B) B/P metagene of group 977A were used to stratify patients into low $\left(P^{L}\right)$, intermediate $\left(P^{\prime}\right)$ and high $\left(P^{H}\right)$ expression tertiles. Kaplan-Meier plots showing distant metastasis-free survival of patients grouped according to the B/P metagene tertiles are shown for each of the proliferation tertiles: (C) low, (D) intermediate and (E) high. Log-rank test $P$-values are shown. B/P: B cell/plasma cell metagene; DMFS: distant metastasis-free survival.

correlated (that is, they are subcomponents of a larger immune gene cluster), suggesting the possibility that the metagenes could exhibit prognostic redundancy, as previously hypothesized [30]. To address this question, we compared the prognostic significance of the immune metagenes to one another via multivariable analysis. We constructed Cox regression models inclusive of pairwise combinations of the metagenes or all three metagenes, simultaneously (Table 3 ). In all pair-wise comparisons (models 1 to 3 ), the metagenes contributed significant independent prognostic information reflective of their non-redundant contributions to prognosis. In a fully combined model (model 4 ), the $\mathrm{B} / \mathrm{P}$ and $\mathrm{M} / \mathrm{D}$ metagenes exhibited the greatest non-redundant prognostic power. Additionally, we assessed the prognostic contributions of the immune metagenes in the presence of conventional variables including nodal status, $\mathrm{T}$ stage (tumor size), histologic grade, age, ER status and treatment status (Table 4). While the majority of variables showed moderately to highly significant associations with DMFS by univariable analysis, in the combined model, only the $\mathrm{B} / \mathrm{P}$ metagene, nodal status, tumor size and treatment remained significant, with greatest significance observed for the $\mathrm{B} / \mathrm{P}$ metagene $(P=$ 0.0001). Together, these findings demonstrate that the immune gene signatures capture distinct aspects of patient prognosis with the $\mathrm{B} / \mathrm{P}$ signature, in particular, imparting the most significant and additive prognostic power in highly proliferative breast cancer compared to the other immune metagenes and conventional prognostic markers.

Immune metagenes risk stratify aggressive clinical and intrinsic subtypes

Next we investigated the impact of the immune metagenes on conventional clinical breast cancer subtypes 
(ER+ or ER-) and the Sorlie-Perou intrinsic molecular subtypes [31]. First, we examined the distribution of the molecular subtypes as a function of the proliferation metagene (Additional file 10). As expected, the least aggressive subtype, luminal A (LumA,) was found predominately in the low and intermediate proliferation tertiles, whereas the more aggressive luminal B (LumB), Basal-like, and human epidermal growth factor receptor 2-enriched (HER2-E) subtypes were most abundant in the high proliferation tertile. When analyzed for associations with DMFS, all three immune metagenes retained significant prognostic power in the Basal-like, LumB and HER2-E subtypes $\left(\mathrm{P}^{\mathrm{H}}\right.$ tertile). This is illustrated by the $\mathrm{B} / \mathrm{P}$ metagene in Additional file 10, and described further in Table 5.

In light of recent work illuminating prognostic roles for immune-related genes in specific pathological contexts such as ER- or HER2+ breast cancer [17,30,32,33], we asked whether the prognostic performance of the immune metagenes was exclusive to the high proliferation tertile in specific tumor subtypes (Table 5). In clinical ER- tumors and Basal-like breast tumors alike, all three immune metagenes were positively associated with DMFS in the high proliferation tertile $\left(\mathrm{P}^{\mathrm{H}}\right)$ and also the intermediate proliferation tertile $\left(\mathrm{P}^{\mathrm{I}}\right)$ - the latter observation indicating that tumor subtype modifies the proliferation dependency of the immune metagenes' prognostic impact. In LumB tumors, the T/NK and $\mathrm{M} /$ $\mathrm{D}$ metagenes (but not $\mathrm{B} / \mathrm{P}$ ) also trended towards or reached significance, respectively, in the $\mathrm{P}^{\mathrm{I}}$ tertile, whereas no metagene achieved significance in the $\mathrm{P}^{\mathrm{I}}$ tertile of the ER+, LumA or HER2-E tumor subtypes. The Claudin-Low (CL) subtype is a rare subset of Basal-like breast tumors with distinguishing features such as high immune cell infiltrate, stem cell-like features and properties characteristic of epithelial-to-mesenchymal transition $[34,35]$. We identified $92 \mathrm{CL}$ tumors in our dataset. Unlike other Basal-like tumors, which tend to be highly proliferative, we observed a fairly uniform distribution of CL tumors across the proliferation tertiles, and as expected, the CL tumors showed a bias towards belonging to the upper tertiles of the immune metagenes (data not shown). However, the immune metagenes were not found to be prognostic in CL tumors as a whole, nor in the intermediate or high proliferation tertiles (comprising only 22 cases and 39 cases, respectively). In the low proliferation tertile $\left(\mathrm{P}^{\mathrm{L}}\right)$, we observed an unexpected inverse survival association for some immune metagenes, such as the T/NK metagene, which achieved statistical significance in the low-proliferating ER-, LumB and $\mathrm{CL}$ subtypes. Together, these data suggest that the prognostic impact of the immune metagenes in breast cancer are both proliferation- and subtype-dependent, and may signal either good or poor outcome depending on the tumor's proliferative configuration and subtype context.

\section{Immune cell metagenes are prognostic across treatment regimens}

Given the potential of the immune metagenes for additive prognostic effects, we asked if simple tertile-based metrics might shed light on the prognostic interplay between the metagenes and if such interactions could form the basis of an integrated model for patient prognosis in treatment-specific contexts. Focusing on the $\mathrm{P}^{\mathrm{H}}$ tertile $(n=657)$, we explored the prognostic attributes of specific combinations of low and high tertiles among the three immune metagenes, without applying mathematical optimization or weighting strategies. As shown in Figure 5A (left panel), we observed that patients having one, two or three low immune tertiles all had relatively poor outcomes, ranging from $41 \%$ to $52 \%$ DMFS at 8 years. No significant survival differences were observed between patients having one, two or three low immune tertiles. Conversely, having high tertiles for all three metagenes was significantly more favorable than having only two or one high tertile assignments (middle panel). Moreover, having high tertiles for all three metagenes was statistically significantly more favorable than having two high tertiles plus an intermediate tertile (that is, for the remaining metagene) or having two high tertiles plus a low tertile (right panel). These observations suggest that a tumor exhibiting a low tertile for any one of the three immune metagenes portends a poor survival outcome that trumps the benefit of having one, or even two, high immune tertiles among the other two metagenes.

Next, we examined how this classification model might impact patient prognosis in specific therapeutic populations (Figure 5B). Lymph node-negative (LN-) patients who did not receive adjuvant therapy after surgery (left panel) exhibited a marked reduction in 10-year DMFS if their tumors displayed one or more low immune tertiles (green survival curve). In ER+, LNpatients who received tamoxifen monotherapy, the group with consistently high immune tertiles (red curve, middle panel) exhibited highly favorable outcomes (> 90\% 10-year DMFS). A group with similarly favorable prognosis (identified by three high immune tertiles) was also observed in patients with highly proliferative ERand Basal-like breast cancer who received adjuvant chemotherapy (red curve, right panel). The majority of these cases would be clinically classified as triple negative breast cancer - a particularly aggressive and treatment-limited form of the disease. These data suggest that the classification of patients according to immune 
A. B/P metagene:
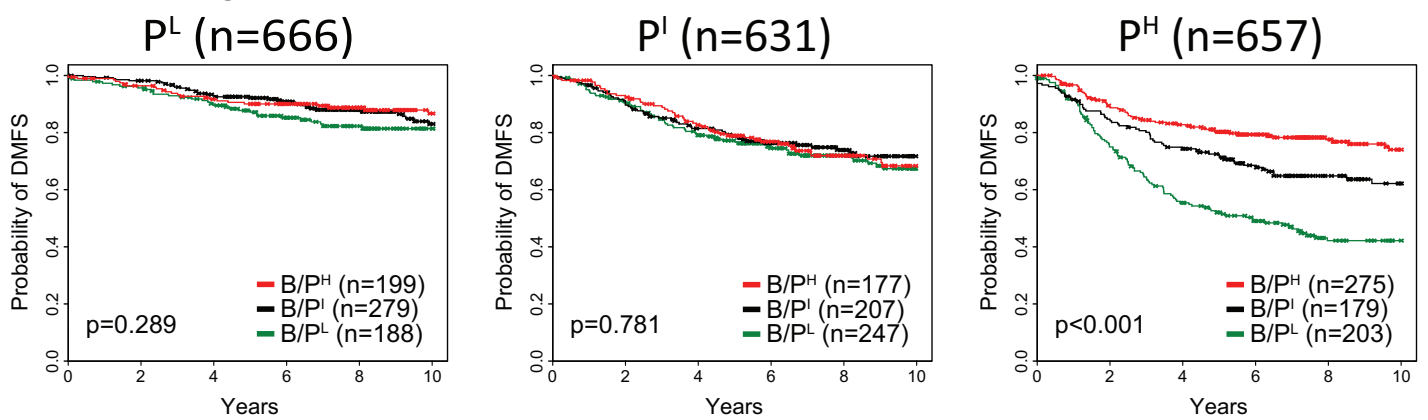

B. T/NK metagene:
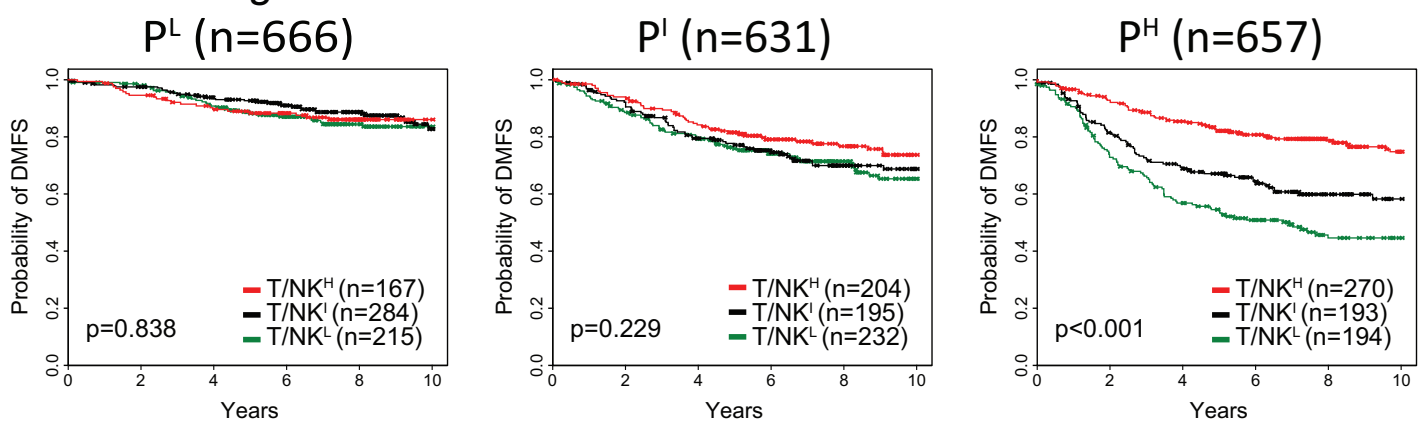

C. M/D metagene:
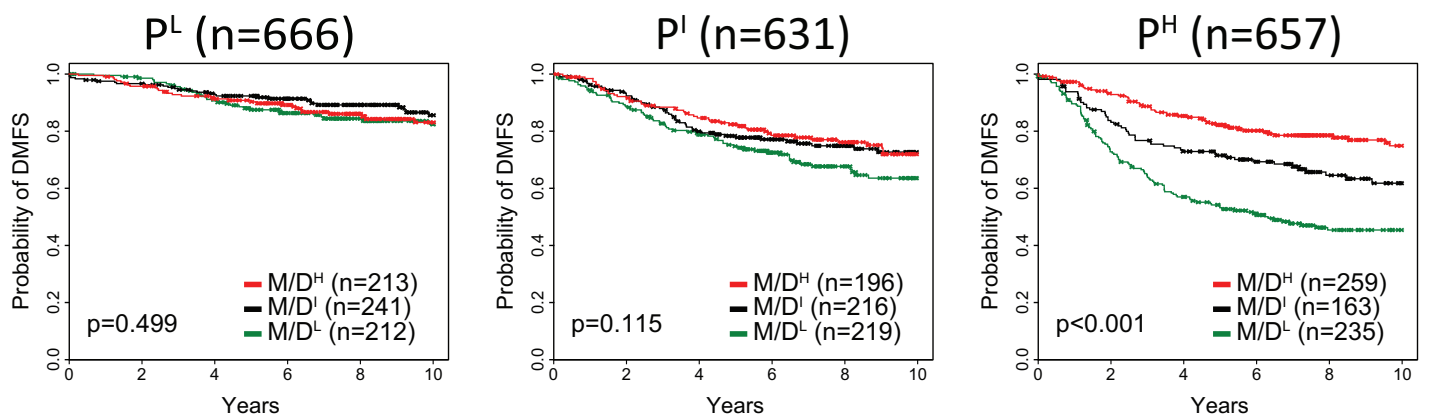

Figure 4 Analysis of the immune metagenes in 1,954 breast cancer cases. Test cases were assigned to proliferation and immune tertiles based on the training set parameters and the results combined for an integrated survival analysis. Shown are Kaplan-Meier survival estimates of the (A) B/P, (B) T/NK and (C) M/D metagene tertiles as they stratify the low, intermediate and high proliferation tertiles. Log-rank test $P$-values are shown. B/P: B cell/plasma cell metagene; M/D: monocytes and dendritic cell metagene; T/NK: T cell and natural killer cell metagene.

metagenes can impact patient prognosis in ways that could influence treatment decisions for certain therapeutic subgroups.

\section{Discussion}

The immune contexture of human cancer, defined as the abundance, location and functional orientation of tumor-infiltrating immune cells [36,37], is gaining recognition as a principal determinant of the biological and clinical behavior of many cancer types. Although it is well-established that the immune contexture may elicit both pro- and anti-tumorigenic responses, a growing body of evidence indicates that the presence of abundant tumor-infiltrating leukocytes, within established tumors, foretells favorable prognosis. This association has been rigorously documented for a number of malignancies, most notably cancers of the skin $[38,39]$, ovary [40,41], colon [42-45] and breast [20-22], underscoring the broad protective effects of anti-cancer immunosurveillance [46-48].

In this work, we investigated the prognostic relevance of transcriptomic footprints of the immune contexture of breast cancer and identified both immune and biological configurations of breast cancer with distinct prognostic attributes. Historically, immunohistochemical measures of the relative abundance of infiltrating 
Table 3 Multivariable survival analysis with immune metagenes in the high proliferation tertile.

\begin{tabular}{|c|c|c|}
\hline \multirow{2}{*}{$\begin{array}{l}\mathrm{P}^{\mathrm{H}}(n=657) \\
\text { Variables }\end{array}$} & \multicolumn{2}{|c|}{ Multivariate } \\
\hline & $\begin{array}{l}\text { Hazard ratio } \\
(95 \% \mathrm{Cl})^{2}\end{array}$ & $P$-value ${ }^{3}$ \\
\hline \multicolumn{3}{|l|}{ Model 1} \\
\hline$B / P(L, I, H)^{1}$ & 0.72 (0.58 to 0.89$)$ & 0.003 \\
\hline T/NK (L, I, H) & 0.73 (0.59 to 0.90$)$ & 0.003 \\
\hline \multicolumn{3}{|l|}{ Model 2} \\
\hline$B / P(L, I, H)$ & 0.73 (0.62 to 0.89$)$ & 0.002 \\
\hline$M / D(L, I, H)$ & 0.70 (0.57 to 0.85$)$ & 0.0004 \\
\hline \multicolumn{3}{|l|}{ Model 3} \\
\hline T/NK $(L, I, H)$ & 0.77 (0.60 to 0.99$)$ & 0.04 \\
\hline$M / D(L, I, H)$ & $0.70(0.55$ to 0.90$)$ & 0.006 \\
\hline \multicolumn{3}{|l|}{ Model 4} \\
\hline$B / P(L, I, H)$ & 0.76 (0.61 to 0.94$)$ & 0.01 \\
\hline$M / D(L, I, H)$ & 0.75 (0.58 to 0.97$)$ & 0.03 \\
\hline T/NK $(L, I, H)$ & 0.88 (0.67 to 1.15$)$ & 0.34 \\
\hline
\end{tabular}

${ }^{1}$ metagene tertiles (L: low; I: intermediate; H: high); ${ }^{2}$ 95\%. B/P: B cell/plasma cell metagene; M/D: monocytes and dendritic cell metagene; T/NK: T cell and natural killer cell metagene.

immune cells in breast tumors, viewed as non-specific infiltrate or as specific leukocyte subpopulations (such as CD8+ T cells), have led to some controversy with regard to the role of the immune system in patient prognosis [20,49-52]. However, prominent immune cell infiltrate observed within late-stage, high-grade, or lymph node-positive breast cancers has consistently been associated with recurrence-free survival of patients [20,51-54]. More recently, we and others have employed bioinformatic strategies to investigate the biological underpinnings of genes associated with breast cancer outcomes [15-19]. A common finding among these studies was the favorable prognosis associated with high expression of various immune-related gene cassettes representing admixed immune cell populations $[15,19,55,56]$ or B cell-enriched $[18,30,32,57]$ or T cellenriched $[17,18,33]$ cell populations, specifically, among ER- or HER2+ breast cancer patients $[15,17,19,30,32,33,55-57]$. In the current work, we demonstrate for the first time that a proliferation metagene reflecting tumor proliferative capacity can sharply demarcate breast cancer cases into proliferative subclasses (low, intermediate and high) where the prognostic attributes of immune gene signatures are differentially manifested.

We identified three distinct expression vectors, or metagenes, within breast tumors that distinguish different tumor-infiltrating leukocyte populations: the $\mathrm{B} / \mathrm{P}$ metagene (B cells/plasma cells); the T/NK metagene ( $\mathrm{T}$ cells/natural killer cells); and the M/D metagene (monocytes/dendritic cells). While analysis at the population level revealed that the prognostic power of each immune metagene was uniformly restricted to tumors comprising the $\mathrm{P}^{\mathrm{H}}$ tertile, analysis by intrinsic subtypes further defined the prognostic orientation of the immune metagenes. For example, the immune metagenes were not associated with DMFS in CL and LumA subtypes of the $\mathrm{P}^{\mathrm{H}}$ tertile, although the small number of cases examined ( $n=39$ and $n=20$, respectively) may have been statistically limiting. Conversely, the immune metagenes were significantly prognostic in both the $\mathrm{P}^{\mathrm{H}}$ and $\mathrm{P}^{\mathrm{I}}$ tertiles in the ER-, Basal-like and LumB subtypes. An interesting and unexpected finding was the prognostic implications of the immune metagenes in the $\mathrm{P}^{\mathrm{L}}$ ER-, Basal-like and LumB tumors comprising 13\%, 9\% and $7 \%$ of their respective populations. Not only were the immune metagenes not associated with favorable prognosis in the $\mathrm{P}^{\mathrm{L}}$ tertile, but statistically significant poor-

Table 4 Univariable and multivariable survival analysis with immune metagenes and conventional variables in the high proliferation tertile.

\begin{tabular}{|c|c|c|c|c|}
\hline \multirow{2}{*}{$\begin{array}{l}\mathrm{P}^{\mathrm{H}}(n=421) \\
\text { Variables }\end{array}$} & \multicolumn{2}{|c|}{ Univariable } & \multicolumn{2}{|c|}{ Multivariable } \\
\hline & $\begin{array}{c}\text { Hazard ratio } \\
(95 \% \mathrm{Cl})^{7}\end{array}$ & $P$-value ${ }^{8}$ & $\begin{array}{l}\text { Hazard ratio } \\
\quad(95 \% \mathrm{Cl})\end{array}$ & $P$-value \\
\hline$\overline{B / P(L, I, H)^{1}}$ & 0.55 (0.45 to 0.66$)$ & $<0.0001$ & 0.59 (0.45 to 0.78$)$ & 0.0001 \\
\hline$M / D(L, I, H)$ & $0.62(0,51$ to 0.75$)$ & $<0.0001$ & 0.89 (0.65 to 1.21$)$ & 0.45 \\
\hline T/NK $(L, I, H)$ & $0.62(0.51$ to 0.75$)$ & $<0.0001$ & 0.98 (0.71 to 1.35$)$ & 0.9 \\
\hline LN Status $(-,+)^{2}$ & 1.38 (0.99 to 1.94$)$ & 0.06 & $1.75(1.12$ to 2.74$)$ & 0.01 \\
\hline Tumor Size $(T 1, T 2, T 3)^{3}$ & 1.37 (1.02 to 1.85$)$ & 0.04 & $1.44(1.05$ to 1.97$)$ & 0.02 \\
\hline Histologic Grade $(1,2,3)^{4}$ & 0.72 (0.54 to 0.95$)$ & 0.02 & 0.80 (0.59 to 1.08$)$ & 0.14 \\
\hline Age $(\leq 40 \mathrm{yrs},>40 \mathrm{yrs})^{5}$ & $1.26(0.83$ to 1.91$)$ & 0.28 & 1.19 (0.73 to 1.72$)$ & 0.61 \\
\hline ER Status $(+,-)^{6}$ & 0.68 (0.49 to 0.96$)$ & 0.03 & $0.87(0.60$ to 1.26$)$ & 0.46 \\
\hline Systemic Treatment (no, yes) & $1.02(0.74$ to 1.41$)$ & 0.89 & 1.56 (1.02 to 2.39$)$ & 0.04 \\
\hline
\end{tabular}

${ }^{1}$ metagene tertiles (L: low; I: intermediate; H: high); ${ }^{2}$ lymph node status (negative or positive); ${ }^{3}$ tumor size by American Joint Committee on Cancer criteria (T1 $\leq$ $2 \mathrm{~cm}$, T2 $>2 \mathrm{~cm}$ but $\leq 5 \mathrm{~cm}$, T3 $>5 \mathrm{~cm}$ ); ${ }^{4}$ Nottingham histologic grade (1: well differentiated, 2: moderately differentiated, 3: poorly differentiated); ${ }^{5}$ age at diagnosis; ${ }^{6}$ estrogen receptor status (positive or negative); ${ }^{7} 95 \%$ confidence interval; ${ }^{8}$ likelihood ratio test. B/P: B cell/plasma cell metagene; M/D: monocytes and dendritic cell metagene; T/NK: T cell and natural killer cell metagene. 
Table 5 Univariable survival analysis of immune metagenes stratified by subtype and proliferation tertile.

\begin{tabular}{|c|c|c|c|c|c|c|}
\hline \multirow[t]{2}{*}{ Subtype } & \multicolumn{2}{|l|}{$\mathrm{P}^{\mathrm{L}}$} & \multicolumn{2}{|l|}{$P^{\prime}$} & \multicolumn{2}{|l|}{$\mathrm{P}^{\mathrm{H}}$} \\
\hline & HR $(95 \% C l)$ & $P$-value ${ }^{2}$ & HR $(95 \% \mathrm{Cl})$ & $P$-value & HR $(95 \% \mathrm{Cl})$ & $P$-value \\
\hline$E R-$ & \multicolumn{2}{|l|}{$n=51^{3}$} & \multicolumn{2}{|c|}{$n=101$} & \multicolumn{2}{|c|}{$n=249$} \\
\hline$B / P(L, I, H)^{1}:$ & 0.81 (0.33 to 2.00$)$ & 0.65 & 0.60 (0.41 to 0.89$)$ & 0.01 & 0.63 (0.48 to 0.83 ) & 0.001 \\
\hline T/NK $(L, I, H):$ & $3.67(1.13$ to 11.9$)$ & 0.01 & 0.54 (0.38 to 0.78$)$ & 0.001 & 0.59 (0.44 to 0.78 ) & 0.0003 \\
\hline$M / D(L, I, H):$ & 3.90 (1.28 to 11.9$)$ & 0.003 & 0.65 (0.45 to 0.94$)$ & 0.02 & 0.59 (0.45 to 0.78$)$ & 0.0002 \\
\hline$E R+$ & \multicolumn{2}{|l|}{$n=542$} & \multicolumn{2}{|c|}{$n=458$} & \multicolumn{2}{|c|}{$n=343$} \\
\hline$B / P(L, I, H):$ & 0.77 (0.56 to 1.04$)$ & 0.09 & 1.03 (0.81 to 1.30$)$ & 0.83 & 0.56 (0.45 to 0.69$)$ & $<0.0001$ \\
\hline T/NK $(L, I, H):$ & $0.80(0.59$ to 1.10$)$ & 0.17 & 0.98 (0.78 to 1.23$)$ & 0.85 & 0.60 (0.48 to 0.73 ) & $<0.0001$ \\
\hline$M / D(L, I, H):$ & 0.86 (0.64 to 1.16$)$ & 0.33 & 0.93 (0.74 to 1.18$)$ & 0.57 & 0.59 (0.48 to 0.73$)$ & $<0.0001$ \\
\hline Basal-like & \multicolumn{2}{|l|}{$n=40$} & \multicolumn{2}{|c|}{$n=113$} & \multicolumn{2}{|c|}{$n=307$} \\
\hline$B / P(L, I, H):$ & 0.97 (0.47 to 2.02) & 0.94 & 0.64 (0.43 to 0.96$)$ & 0.03 & 0.67 (0.52 to 0.85$)$ & 0.001 \\
\hline T/NK $(L, I, H):$ & 1.63 (0.68 to 3.95$)$ & 0.23 & 0.48 (0.33 to 0.69$)$ & 0.0002 & 0.65 (0.51 to 0.83 ) & 0.0006 \\
\hline$M / D(L, I, H):$ & 1.87 (0.74 to 4.72 ) & 0.14 & 0.54 (0.37 to 0.79$)$ & 0.002 & 0.60 (0.47 to 0.77$)$ & $<0.0001$ \\
\hline HER2-E & \multicolumn{2}{|l|}{$n=14$} & \multicolumn{2}{|l|}{$n=66$} & \multicolumn{2}{|c|}{$n=94$} \\
\hline$B / P(L, I, H):$ & 0.70 (0.17 to 2.85$)$ & 0.62 & 0.72 (0.46 to 1.14$)$ & 0.16 & 0.51 (0.34 to 0.78) & 0.002 \\
\hline T/NK $(L, I, H)$ : & 0.08 (0.007 to 0.9$)$ & 0.02 & 0.79 (0.53 to 1.16$)$ & 0.23 & 0.46 (0.31 to 0.68 ) & 0.0001 \\
\hline$M / D(L, I, H):$ & 0.66 (0.24 to 1.85$)$ & 0.43 & 0.96 (0.64 to 1.46$)$ & 0.86 & 0.53 (0.36 to 0.78$)$ & 0.001 \\
\hline Luminal B & \multicolumn{2}{|l|}{$n=26$} & \multicolumn{2}{|l|}{$n=135$} & \multicolumn{2}{|c|}{$n=212$} \\
\hline$B / P(L, I, H):$ & 2.28 (0.82 to 6.32) & 0.11 & 0.97 (0.65 to 1.43$)$ & 0.86 & 0.52 (0.38 to 0.71$)$ & $<0.0001$ \\
\hline T/NK $(L, I, H):$ & 2.81 (1.06 to 7.49$)$ & 0.03 & 0.68 (0.43 to 1.08$)$ & 0.09 & 0.60 (0.45 to 0.80 ) & 0.0002 \\
\hline$M / D(L, I, H):$ & 2.23 (0.83 to 5.96$)$ & 0.11 & 0.50 (0.30 to 0.83$)$ & 0.003 & 0.57 (0.42 to 0.77$)$ & $<0.0001$ \\
\hline Luminal $A$ & \multicolumn{2}{|l|}{$n=347$} & \multicolumn{2}{|c|}{$n=200$} & \multicolumn{2}{|c|}{$n=20$} \\
\hline$B / P(L, I, H):$ & 0.71 (0.44 to 1.13 ) & 0.14 & 0.95 (0.58 to 1.56$)$ & 0.83 & 1.41 (0.52 to 3.86$)$ & 0.50 \\
\hline T/NK $(L, I, H)$ : & 0.57 (0.33 to 0.97$)$ & 0.03 & 1.08 (0.68 to 1.72 ) & 0.73 & 0.98 (0.34 to 2.79 ) & 0.96 \\
\hline$M / D(L, I, H):$ & 0.70 (0.44 to 1.12$)$ & 0.13 & 1.10 (0.71 to 1.71$)$ & 0.66 & $1.45(0.44$ to 4.79$)$ & 0.55 \\
\hline Claudin-Low & \multicolumn{2}{|l|}{$n=31$} & \multicolumn{2}{|l|}{$n=22$} & \multicolumn{2}{|c|}{$n=39$} \\
\hline$B / P(L, I, H):$ & 2.1 (0.53 to 8.00) & 0.24 & 1.5 (0.59 to 3.79) & 0.38 & 1.06 (0.56 to 2.03) & 0.85 \\
\hline T/NK (L, I, H): & $>100$ (0.00 to +inf) & 0.02 & $0.70(0.28$ to 1.74$)$ & 0.45 & 0.87 (0.44 to 1.73 ) & 0.69 \\
\hline$M / D(L, I, H):$ & $>100(0.00$ to + inf $)$ & 0.05 & 0.63 (0.24 to 1.63$)$ & 0.36 & 0.78 (0.43 to 1.44$)$ & 0.44 \\
\hline
\end{tabular}

${ }^{1}$ metagene tertiles (L: low; I: intermediate; $\mathrm{H}$ : high); ${ }^{2}$ likelihood ratio test $P$-value; ${ }^{3}$ number of cases in specified subtype and proliferation tertile. Cl: confidence interval; ER: estrogen receptor-positive breast cancer; HER2-E: human epidermal growth factor receptor 2-enriched; HR: hazard ratio.

outcome associations were observed, particularly for the $\mathrm{T} / \mathrm{NK}$ metagene. That these observations were made in relatively small sample populations (ranging from 26 to 51 cases) necessitates caution when interpreting the results. However, that the poor-outcome association of the $\mathrm{T} / \mathrm{NK}$ metagene achieved statistical significance in both the ER- and LumB (ER+) subpopulations suggests the possibility of the existence of a low proliferationassociated, ER-independent tumor phenotype where T cell and/or natural killer cell abundance may signify pro-metastatic rather than anti-metastatic behavior. By contrast, in the LumA tumors of the $\mathrm{P}^{\mathrm{L}}$ tertile $(n=$ 347 ), all three immune metagenes trended towards associations with favorable DMFS, with the T/NK metagene achieving statistical significance. Together, these observations paint a complex picture of how tumor-immune cell interactions regulate malignant progression and suggest that the pro- or anti-tumorigenic properties of infiltrating immune cells vary not only with the proliferative status of the tumor, but are determined, in part, by factors associated with intrinsic subtype.

How tumor proliferation rate relates to pro- or anticancer immune cell behavior has, to our knowledge, not been studied; however, it is plausible that proliferation status could act as a surrogate for one or more immunomodulatory pathological contexts. For example, it has been widely observed that, in breast cancer, the rates of proliferation and cell death are positively correlated [58-61]. Apoptosis and necrosis are associated with both enhanced lymphocytic infiltrate in breast cancer [60] and enhanced immunogenic response [62-64]. Thus, cell death that increases available tumor antigen may attract antigen-presenting cells that in turn recruit and/or activate $\mathrm{T}$ and $\mathrm{B}$ cells in the tumor. Furthermore, increased angiogenesis [65], which supports increased proliferation, may allow better tumor access by immune cells. These possibilities may explain, in part, the high rate of recurrence-free survival observed in the high immune 
A. $P^{H}$ : immune tertile combinatorial analysis
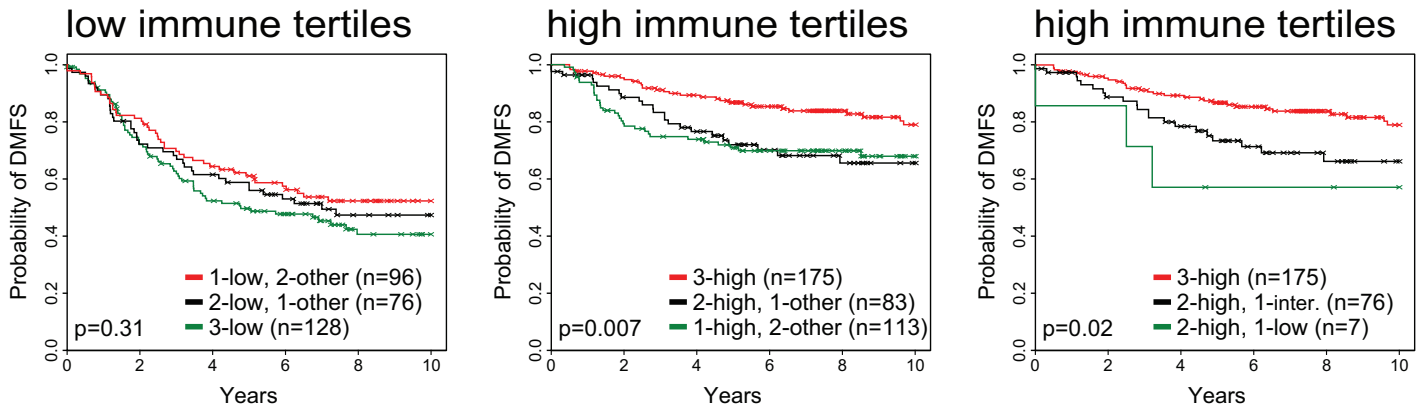

\section{B. $P^{H}$ : combinatorial analysis in treatment subgroups}
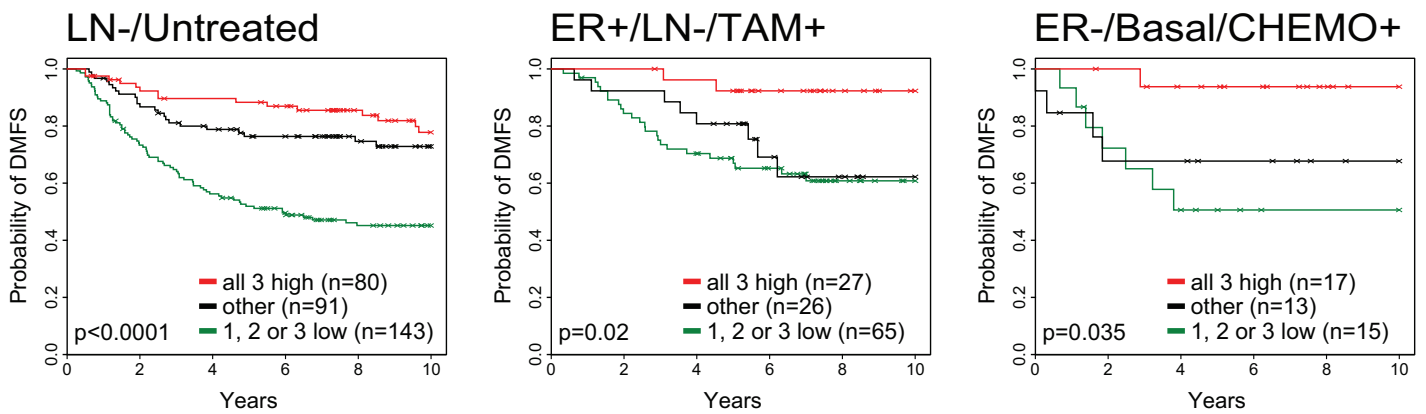

Figure 5 Combinatorial analysis of immune tertile configurations in prognosis of highly proliferative breast cancer. (A) The prognostic impact of combinations of low and high immune metagene tertiles are investigated by Kaplan-Meier analysis. (B) Kaplan-Meier plots illustrate the prognostic attributes of low and high immune tertile combinations in specific therapeutic subgroups of patients. Log-rank test $P$-values are shown. ER: estrogen receptor; LN: lymph node; TAM: tamoxifen monotherapy; CHEMO: chemotherapy.

metagene tertiles of highly proliferative breast cancer. Furthermore, a reduced proliferative (and apoptotic) capacity could reflect a tumor microenvironment more conducive to immunosuppression, and subsequently, poorer survival outcomes. In such an instance, for example, $\mathrm{CD} 4+/ \mathrm{FOXP} 3+\mathrm{T}$ regulatory cells may predominate over $\mathrm{CD} 8+$ cytotoxic $\mathrm{T}$ cells. The abundance and location of tumor-infiltrating $\mathrm{T}$ regulatory cells, as well as their ratio with cytotoxic $\mathrm{T}$ cells, have previously been shown to associate with poor breast cancer outcomes [66-69].

Most previously described immune gene signatures discovered in microarray analyses (including the metagenes described herein) trace back to a common origin for their discovery: a gene cluster of approximately 600 genes highly expressed by tumor-infiltrating leukocytes and whose expression patterns form a larger, diverse immune gene cluster when analyzed in bulk tumor tissues [17]. However, the different gene selection methodologies used, and the variation in size and composition of patient populations examined, may together explain the diversity in gene make-up across the reported signatures, as well as conflicting observations regarding the prognostic performances of similarly derived immune gene cassettes [17]. For example, we and others have observed that not all genes of this larger immune gene cluster are prognostic of breast cancer survival, with some carrying substantially more prognostic weight than others. Although the unsupervised gene selection methods used in previous studies have demonstrated predictive power of the immune genes, the supervised strategy we employed (that is, selecting genes with significant DMFS associations prior to metagene construction) enabled the parsing out of the immune genes with greatest prognostic strength. These genes may point not only to specific cellular components of the immune contexture, but also to immunological functional orientations required for tumor rejection. A more precise assessment of the cellular origins and functional attributes of these genes is needed.

Rody and colleagues [17] deconstructed the larger immune gene cluster into seven metagenes that appeared to reflect various components of the immune system. In multivariable analysis, only a $T$ cell-related metagene was found to be significantly correlated with disease-free survival $(P=0.01)$ when considering a mixed population of 1,263 patients with breast cancer; consequently, this was the metagene carried forward for 
further analysis in ER and HER2 status-specific populations. By contrast, our multivariable analysis revealed that multiple immune metagenes may contribute additive prognostic information when considered in combination with one another. This is likely due in part to our focus on immune genes with a priori associations with DMFS, as well as the fact that our analysis was confined to the highly proliferative breast tumors as defined by our proliferation metagene, while that of Rody and colleagues was not restricted to the more proliferative cases. Furthermore, the composition of our immune metagenes also varied with those of Rody and colleagues. Although $80 \%$ of the probe sets comprising our B/P metagene overlapped with the Rody IgG (B cell) metagene, only $60 \%$ of our $\mathrm{T} / \mathrm{NK}$ probe sets overlapped with the Rody LCK ( $\mathrm{T}$ cell) metagene, and our M/D metagene comprised of novel probe sets not selected by their methods.

Our observation that the prognostic attributes of the immune metagenes are largely non-redundant may reflect the importance of cooperative interplay among different immune cell types in metastasis-protective immunity. Indeed, proteins critical for such interactions are evidenced in the composition of our metagenes. For example, CD27, a component of the T/NK metagene, encodes a type I transmembrane protein of the tumor necrosis factor receptor superfamily that plays key roles in the expansion and memory of activated CD8+ killer $\mathrm{T}$ cells $[70,71]$ as well as B-cell activation and immunoglobulin synthesis [72,73]. In natural killer cells, high expression of CD27 is associated with greater effector function and enhanced interaction with dendritic cells compared to CD27-low natural killer cells that exhibit a higher stimulation threshold and express inhibitory receptors [74]. Moreover, the M/D metagene comprises a number of MHC class II (HLA) alpha and beta chain paralogs expressed by professional antigen-presenting cells. The products of these genes present extracellular antigens to $\mathrm{T}$ lymphocytes thereby stimulating expansion of $\mathrm{T}$ helper cells and, subsequently, the downstream activation of plasma B cells. If such interactions are essential to the maintenance of DMFS, this could explain our observation that patients having even a single low tertile immune metagene assignment are unlikely to achieve a durable remission (Figure 5A).

Tertile-based cut-points were used in our analysis to characterize prognostic interactions in broad terms, not to develop optimized prognostic classifiers. Nevertheless, we observed that the tertiles could be used to identify significant therapy-relevant risk groups. ER+, LN- breast cancer is frequently treated with hormonal therapy alone or in combination with chemotherapy. In recent years, the decision to withhold chemotherapy from a fraction of these patients has been justified by the 21- gene Oncotype Dx test (Genomic Health, Inc.) which relies on a gene-based classification algorithm. Because proliferation genes carry the greatest prognostic weight in this algorithm $[10,11]$, it is not surprising that virtually all of the highly proliferative cases are assigned to the high and intermediate risk groups where the use of chemotherapy is indicated. Interestingly, we observed that about $23 \%$ of the highly proliferative, ER+, LNcases possessed high tertiles for all three immune metagenes, and subsequently exhibited excellent 10 -year DMFS following tamoxifen monotherapy. This high survival rate of this group (>90\% at 10 years) is similar to the disease-free survival rate of the Oncotype Dx lowrisk group [10]. This indicates that the immune metagenes may have value in identifying a second low-risk fraction of patients from among the highly proliferative (high Oncotype Dx recurrence score) cases who might also be spared unnecessary chemotherapy. Furthermore, this same high tertile immune metagene profile identified patients with ER-, Basal-like breast cancer (predominantly triple negative breast cancer) that would have excellent 10-year survival following adjuvant chemotherapy. By contrast, cases associated with one or more low immune metagenes exhibited $>50 \%$ probability of distant metastasis before 5 years. Thus, the immune metagenes could aid in the selection of patients most in need of, and most suitable for the testing of, new therapeutic agents being evaluated in clinical trials. It should be noted that these prognostic observations may reflect some bias related to historical treatment standards such as the use of adjuvant CMF (cyclophosphamide, methotrexate and 5-fluorouracil), FAC (5-fluorouracil, doxorubicin and cyclophosphamide) and AC (cyclophosphamide and doxorubicin). In recent years, the addition of taxanes to chemotherapeutic regimens has reduced the rate of breast cancer relapseby $10 \%$ to $15 \%$. Thus, the extent to which the immune metagenes would retain prognostic value in light of today's taxaneinclusive regimens warrants prospective evaluation. Furthermore, mounting evidence that anthracyclines and taxanes both possess immunomodulatory activity that impacts treatment efficacy [75-78] provides further rationale for investigating the clinical importance of the immune metagenes in patients treated with chemotherapy. Finally, further work will be necessary to determine the optimal diagnostic platform for immune metagene assessment, as well as the precise metagene thresholds that provide maximal prognostic utility within specific breast tumor subtypes.

\section{Conclusions}

Gene expression profiles that quantify immune cell abundance within breast tumors are prognostic of DMFS. The prognostic value of these signatures does 
not manifest in all tumor types, but rather can be stratified by tumor proliferative capacity in a manner that further depends on molecular subtype. Our findings suggest that multiple immune metagenes measured in combination may provide actionable prognostic information for the most aggressive breast cancer phenotypes for which prognostic assays remain lacking. This work sheds new light on the roles of tumor-infiltrating immune cells in safeguarding patients against distant metastasis, and suggests an important and quantifiable interplay between different immune cell populations in establishing long-term, metastasis-protective immunity.

\section{Materials and methods}

\section{Breast cancer microarray datasets}

We assembled a multi-study microarray database of breast tumor expression profiles $(n=2,116)$ based on the Affymetrix U133 GeneChip microarray platform. The database encompasses 15 different breast cancer populations for which corresponding microarray data and clinical annotations were extracted from public data repositories including the Gene Expression Omnibus (National Center for Biotechnology Information, Bethesda, MD, USA) [79], ArrayExpress (European Bioinformatics Institute, Hinxton, Cambridgeshire, UK) and caArray (National Cancer Institute, Bethesda, MD, USA) or by direct communication with study authors. Study population details and literature references are presented in Additional file 1. Previously unpublished breast tumor profiles from Belgium, England and Singapore have been deposited in the Gene Expression Omnibus [79] and are accessible through GEO Series [GEO: GSE45255] [80]. Raw array data (CEL files) were preprocessed and normalized using the $\mathrm{R}$ software package [81] and library files provided by the Bioconductor project. In order to preserve a consistent normalization strategy across all study populations, raw data were MAS5.0 normalized on individual study populations using the justMAS function in the simpleaffy library from Bioconductor [82] (no background correction, mean target intensity of 600 ). The specific array platforms employed were the HG-U133A, HG-U133 PLUS 2.0 and HG-U133A2 gene chips. To ensure equal information content from each chip type, only probe sets common to all chip types were utilized in subsequent analysis. This resulted in the use of 22,268 probe sets that were common to all microarrays in all study populations. Cross-population batch effects were corrected using the COMBAT empirical Bayes method [83]. Of the initial 2,116 tumor profiles, 2,034 profiles represent primary invasive breast tumors sampled at the time of surgical resection, without exposure to neoadjuvant treatment. Of these, 1,954 cases were annotated with DMFS time and event. Other clinical annotation such as treatment type, ER status, nodal status, tumor size, histologic grade and patient age were available for the majority of cases. The pan-leukocyte expression profiles of Abbas et al. [26] were downloaded from the Gene Expression Omnibus [79] [GEO:GSE22886] and MAS5normalized in the same fashion as the breast tumor datasets.

\section{Intrinsic subtype classification}

Intrinsic breast cancer subtypes were assigned to samples using the Single Sample Predictor (SSP) algorithm described by $\mathrm{Hu}$ et al. [84] and utilized by Fan et al. [85]. Affymetrix probe sets were matched to the genes comprising the SSP centroids using UniGene annotation. Prior to batch-correction, the expression data for each gene were mean centered, and Spearman correlation was used to find the centroid most closely associated with each tumor sample. In cases where a correlation greater than 0.1 was not achieved with at least one centroid, a subtype was not assigned to that sample ( $n=92$ cases). Tumors representing the CL subtype were identified using the methods of Prat et al. [35] and the supplementary information from [86]. Briefly, CL centroids were generated using the Prat et al. microarray data set deposited in [GEO:GSE18229], with breast tumor samples assigned to the closest subtype centroid based on Euclidean distance.

\section{Case randomization}

The 1,954 survival-annotated cases were dichotomized into training and testing sets comprising 977 cases each. Cases were iteratively randomized to two groups with monitoring of intergroup survival rates (log-rank test) and standardized differences [87] for the variables: DMFS time, DMFS event, original study population, intrinsic subtype and ER status. The first randomization to achieve the following criteria was selected: log-rank test $P$-value for survival difference $>0.99$, and $<10 \%$ standardized difference for each of the listed variables.

\section{Statistical analyses}

Associations between gene expression and patient survival (DMFS) were assessed by Cox proportional hazards regression (likelihood ratio test) using the $\mathrm{R}$ survival package [88] or by the Kaplan-Meier method (log-rank test, SigmaPlot 11.0). DMFS was defined as the absence of clinically confirmed distant relapse. Data were censored on date of last follow-up (disease-free), date of diagnosis of a second primary cancer, and local or regional relapse without evidence of distant recurrence. To minimize population-specific bias owing to patient follow-up duration, survival analyses were delimited to a 10 -year window of patient follow-up. (Notably, only $1.5 \%$ of cases were annotated for post 10-year 
recurrence, and no convergence of survival curves post 10 years was observed.) Probe sets (genes) with likelihood ratio test $P$-values less than 0.01 and FDR-adjusted q-values less than 0.10 [89] were identified and selected for supervised hierarchical cluster analysis. Univariable, multivariable and Kaplan-Meier analyses were performed in SigmaPlot 11.0. For statistical analyses low, intermediate and high tertile metagene designations were coded as 1, 2 and 3, respectively. All statistical tests were two-sided.

\section{Hierarchical clustering}

Supervised hierarchical clustering and heatmap visualization of breast tumor and leukocyte gene expression profiles were conducted using Eisen's Cluster (v2.11) and TreeView (v1.60) software [90,91]. Briefly, normalized $\log _{2}$ expression data were mean centered (on genes only), and genes and tumors were hierarchically clustered by average linkage using uncentered Pearson correlation as the distance metric. Clustered data were visualized by TreeView using default color saturation settings.

\section{Metagene construction}

Selection and construction of the immune metagenes was carried out essentially as previously described $[17,28]$. Briefly, nested gene correlation structure was determined by the Pearson distance metric and average linkage clustering [91]. The selected subclusters were then defined as the nested branches that generated an approximate average correlation of 0.6. This threshold was chosen to satisfy two primary goals: selection of genes with relatively high magnitude of correlation such that their correlation could not be considered a chance event; and selection of a reasonable number of genes (at least tens of genes) suitable for (GO) enrichment analysis. The metagene value for a given tumor was defined by averaging the signal intensities of the genes comprising each subcluster $[17,28,92]$. In cases where two or more probe sets corresponded to the same gene identity within a subcluster, these probe sets were first averaged together, prior to cross-gene averaging, to guard against overrepresentation of any one gene with respect to its contribution to the metagene value. The metagene value (average signal intensity) thresholds defined by tertile cut-points in the training set are listed in Additional file 11.

\section{QuantiGene analysis of immune genes from FFPE breast tumor tissues}

Thirty FFPE tissue blocks from surgically resected primary ER+ breast tumors were selected from a biobank of primary breast tumors representing recurrent cases and controls (that is, cancers that did not metastasize) maintained at Aarhus University Hospital, Denmark (SJHD and TLL) [93]. The blocks derived from patients with centrally confirmed [94] ER+ stage II breast cancer diagnosed in 2000 or 2001. From each block, three 10micron sections were cut to slides, the first of which was hematoxylin and eosin (H\&E) stained to identify regions of highest tumor cellularity, which were then demarcated on the unstained slides. The H\&E-stained slides were subsequently examined by a tumor pathologist at Wake Forest School of Medicine, NC, USA (MCW) for estimation of total leukocyte infiltrate within the demarcated regions of high tumor cellularity. Two slides were rejected based on evidence of poor preservation. For the remaining 28 samples, total leukocyte content was scored into four categories defined as low/ absent, intermediate-low, intermediate-high, and high (irrespective of spatial considerations such as intratumoral or intra-stromal associations). As proof of principle and to test the technology platform, three genes were selected from each of two of the immune metagenes for analysis by Panomics QuantiGene Plex 2.0 (Affymetrix, Santa Clara, CA, USA)). Genes that displayed strong correlation with their cognate metagene and, simultaneously, large dynamic range of gene expression by microarray were selected for this purpose. Specifically, probe sets were designed to detect IGKC, IGLL5 and IGHA1 (the B/P metagene) and $L C K, C D 3 E$ and $C D 27$ (the T/NK metagene). Four housekeeping genes (ACTB, GAPDH, ACTG1, and EIF4G2) were included for normalization. Normalized expression ratios were generated by dividing the background-subtracted expression values by the geometric mean of the housekeeping genes. Lastly, the expression ratios were averaged to generate metagene values, and these values were correlated to total leukocyte abundance by Pearson correlation.

\section{Gene Ontology enrichment analysis}

The DAVID Bioinformatics Resource (Database for Annotation, Visualization and Integrated Discovery) $[27,95]$ version 6.7 , sponsored by the National Institute of Allergy and Infectious Diseases, National Institutes of Health, was used to investigate the statistical enrichment of biological terms and processes associated with the genes comprising the immune gene clusters. Briefly, Affymetrix probe set unique identifiers were imported into DAVID [96] and the functional annotation tools were utilized as described [95].

\section{Additional material}

Additional file 1: Table S1 - Data table of patient populations

comprising the breast cancer microarray database. Reference data

for each breast cancer population is provided. 
Additional file 2: Spreadsheet S1 - Distant metastasis-free survivalassociated genes selected from patient groups 977A and 977B Selected probe sets and their corresponding Cox regression coefficient, hazard ratio, confidence interval and FDR q-value are shown for 977A (1 $1^{\text {st }}$ tab) and 977B ( $2^{\text {nd }}$ tab).

Additional file 3: Figure S1 - Hierarchical clustering of distant metastasis-free survival-associated genes in group 977B. The heatmap (far left) shows the hierarchical clustering of the 3,304 genes (probe sets) associated with distant metastasis-free survival. A zoomed in view of the proliferation and immune gene clusters are shown with gene dendrograms (right). Clustered genes having average correlations of approximately 0.6 are indicated by colored branches. Heatmap coloring: mean gene expression (signal intensity) is colored black, red indicates above-mean expression, green denotes below-mean expression and the degree of color saturation reflects the magnitude of expression relative to the mean

Additional file 4: Figure S2 - The proliferation metagene score is highly correlated with tumor cell proliferation rate. Two hundred and thirty-two primary breast tumors from the Uppsala population [3] were annotated for markers of proliferation including Ki-67 staining levels (by immunohistochemistry, MIB1 monoclonal antibody) and mitotic index. Shown is the correlation between the (A) proliferation metagene and mitotic index and (B) Ki-67 staining. The metagene is depicted in (C), and tumor samples are ordered (in all figures) from left to right in ascending order, according to the proliferation metagene score (average $\log$ intensity of the proliferation genes). The Pearson product-moment correlation coefficient ( $r$ ) and $P$-value are shown (box insert, A, B).

Additional file 5: Table S2 - Ontology analysis and gene components of the immune gene cluster. Table A: Gene Ontology analysis of 161 gene probe sets comprising the large immune gene cluster demarcated in Figure 1. Table B: Probe sets and their corresponding gene names that comprise the immune gene cluster.

Additional file 6: Spreadsheet S2 - Table of Affymetrix probe sets and corresponding genes that comprise the proliferation and immune metagenes.

Additional file 7: Figure S3 - Concordance among gene clusters derived from patient groups 977A and 977B. (A) Expression patterns of probes comprising the proliferation $(P)$ and immune clusters $(\mathrm{IC})$ were compared between 977A and 977B. All selected probes $(n=210)$ and tumors $(n=1,954)$ were hierarchically clustered, then the tumors were partitioned (in cluster order) by patient group. Genes comprising the proliferation and immune clusters are distinguished by color according to the key shown. (B) Proliferation and immune cluster metagene values (ie, averaged $\log _{2}$ signal intensities; see Methods), derived from 977A and 977B, were compared to one another by Pearson correlation. Pearson coefficients $(r)$ are represented by heatmap and described by the color key. $r$ values corresponding to the cognate clusters are shown in white font. Biological titles equated with the immune clusters elsewhere in the manuscript are shown for continuity.

\section{Additional file 8: Figure S4 - Breast cancer immune and} proliferation gene clusters differentiate specific leukocyte cell types This figure is derived from Figure 2 of the main text, but includes original experimental annotations for each array sample (as labeled in [26]) and includes the genes of the proliferation metagene cluster. Dendrograms are omitted for space.

Additional file 9: Figure S5 - Magnitude of immune metagene expression correlates with abundance of immune cell infiltrate Histological characterization of immune cell abundance was previously conducted for 35 tumors (22 ER+, 13 ER-) from Guy's Hospital, London [29], for which corresponding tumor material was profiled on expression microarrays and included in our multi-study microarray database [97]. (A) Distributions of mean-centered metagene values (977A) are shown as box and whisker plots for each measure of immune cell abundance $(L=$ low, I = intermediate, $H=$ high). Shaded rectangles define the interquartile ranges. The midline of each rectangle marks the median value. T-bars extending from the interquartile range mark the 5 th and 95th percentiles, and outliers are indicated by open circles. $P$-values for differential distributions were generated by Kruskal-Wallis one-way analysis of variance by ranks (Sigma Plot 11.0). (B-D) Genes representative of the T/NK and B/P metagenes were prospectively analyzed for expression in a panel of 28 ER+ breast tumors using the Panomics QuantiGene Plex 2.0 assay system (Affymetrix; see paper Methods). H\&E-stained, FFPE breast tumor samples exhibiting (B) high or (C) low levels of infiltrating immune cells are shown. Red arrows indicate small, darkly staining nuclei of leukocytes; blue arrows mark tumor cell nuclei. (D) Distributions of mean-centered metagene values (based on three representative genes, per metagene) are shown as a function of immune cell abundance $(L=$ low; $1 / L=$ intermediate-low; $1 / H=$ intermediate-high; $\mathrm{H}=$ high). Box and whisker plot parameters and statistical method are the same as for (A).

Additional file 10: Figure S6 - The immune metagenes are prognostic of outcome in the aggressive intrinsic subtypes. (A) Intrinsic subtype distributions are shown (colored vertical bars) relative to the proliferation metagene, whereby tumors are ranked by the proliferation metagene from left to right in ascending order. (B) The percentage of each tumor subtype comprising the three proliferation tertiles is shown. (C) Kaplan-Meier plots show the $\mathrm{P}^{\mathrm{H}}$ HER2-enriched (left), luminal B (middle) and Basal-like (right) populations stratified by the B/P metagene.

Additional file 11: Table S3 - Metagene value thresholds defined by tertile cut-points in the training set and subsequently applied to the test set.

\section{Abbreviations}

B/P: B cell/plasma cell; CL: Claudin-Low; DAVID: database for annotation, visualization and integrated discovery; DMFS: distant metastasis-free survival; ER: estrogen receptor; FDR: false discovery rate; FFPE: formalin-fixed paraffinembedded; GO: Gene Ontology; H\&E: hematoxylin and eosin; HER2-E: and human epidermal growth factor receptor 2-enriched; HLA: human leukocyte antigen; LN: lymph node; LumA: luminal $A$; LumB: luminal $B ;$ M/D: monocyte/dendritic cell; MHC: major histocompatibility; PL, I, H: low, intermediate, or high proliferation tertile; T/NK: T cell/natural killer cell.

\section{Authors' contributions}

SN and LDM conceived of the project and analytical strategy. MAB and LDM qualified and curated the breast cancer microarray datasets. MAB processed the microarray data (for example, normalization, batch-correction) and assigned cases to breast cancer subtypes. JWC contributed to data curation, quality control and subset analysis. JB and CS contributed microarray and clinical data, and contributed to manuscript development. TLL, SJHD and MCW provided paraffin blocks and pathological guidance, and contributed to methods development. SN, JR, PD, JPV and LDM vetted content and wrote the manuscript. All authors read and approved the final manuscript.

\section{Competing interests}

The authors declare that they have no competing interests.

\section{Author details}

'Section of Hematology \& Oncology, Wake Forest School of Medicine, Medical Center Boulevard, Winston-Salem, NC, 27157, USA. '2Department of Biostatistical Sciences, Wake Forest Public Health Sciences, Medical Center Boulevard, Winston-Salem, NC, 27157, USA. ${ }^{3}$ Department of Pathology, Wake Forest School of Medicine, Medical Center Boulevard, Winston-Salem, NC, 27157, USA. ${ }^{4}$ Department of Cancer Biology, Wake Forest School of Medicine, Medical Center Boulevard, Winston-Salem, NC, 27157, USA. ${ }^{5}$ Department of Epidemiology \& Prevention, Wake Forest University Health Sciences, Medical Center Boulevard, Winston-Salem, NC, 27157, USA. ${ }^{6}$ Department of Clinical Epidemiology, Aarhus University Hospital, Noerrebrogade 44, DK-8000 Aarhus C, Denmark. ${ }^{7}$ Institute of Pathology, Aarhus University Hospital, Noerrebrogade 44, DK-8000 Aarhus C, Denmark. ${ }^{8}$ Department of Oncology-Pathology, Cancer Center Karolinska, Radiumhemmet, Karolinska Institutet and University Hospital, S-171 76, Stockholm, Sweden. ${ }^{9}$ University of Manchester, Paterson Institute for Cancer Research, Wilmslow Road, Manchester, M20 4BX, UK. ${ }^{10}$ Université Libre de Bruxelles, Institut Jules Bordet, 121 Boulevard de Waterloo, 1000 Brussels, 
Belgium. " Department of Biochemistry, Otago School of Medical Sciences, University of Otago, 710 Cumberland Street, Dunedin, 9016, New Zealand.

Received: 7 February 2013 Revised: 16 February 2013

Accepted: 29 April 2013 Published: 29 April 2013

\section{References}

1. Dai H, van't Veer L, Lamb J, He YD, Mao M, Fine BM, Bernards R, van de Vijver M, Deutsch P, Sachs A, Stoughton R, Friend S: A cell proliferation signature is a marker of extremely poor outcome in a subpopulation of breast cancer patients. Cancer Res 2005, 65:4059-4066.

2. Ivshina AV, George J, Senko O, Mow B, Putti TC, Smeds J, Lindahl T, Pawitan Y, Hall P, Nordgren H, Wong JE, Liu ET, Bergh J, Kuznetsov VA, Miller LD: Genetic reclassification of histologic grade delineates new clinical subtypes of breast cancer. Cancer Res 2006, 66:10292-10301.

3. Miller LD, Smeds J, George J, Vega VB, Vergara L, Ploner A, Pawitan Y, Hall P, Klaar S, Liu ET, Bergh J: An expression signature for p53 status in human breast cancer predicts mutation status, transcriptional effects, and patient survival. Proc Natl Acad Sci USA 2005, 102:13550-13555.

4. Rosenwald A, Wright G, Wiestner A, Chan WC, Connors JM, Campo E, Gascoyne RD, Grogan TM, Muller-Hermelink HK, Smeland EB, Chiorazzi M, Giltnane JM, Hurt EM, Zhao H, Averett L, Henrickson S, Yang L, Powell J, Wilson WH, Jaffe ES, Simon R, Klausner RD, Montserrat E, Bosch F, Greiner TC, Weisenburger DD, Sanger WG, Dave BJ, Lynch JC, Vose J, et al The proliferation gene expression signature is a quantitative integrator of oncogenic events that predicts survival in mantle cell lymphoma. Cancer Cell 2003, 3:185-197.

5. Sotiriou C, Wirapati P, Loi S, Harris A, Fox S, Smeds J, Nordgren H, Farmer P, Praz V, Haibe-Kains B, Desmedt C, Larsimont D, Cardoso F, Peterse H, Nuyten D, Buyse M, Van de Vijver MJ, Bergh J, Piccart M, Delorenzi M: Gene expression profiling in breast cancer: understanding the molecular basis of histologic grade to improve prognosis. J Natl Cancer Inst 2006, 98:262-272.

6. Whitfield ML, George LK, Grant GD, Perou CM: Common markers of proliferation. Nat Rev Cancer 2006, 6:99-106.

7. Whitfield ML, Sherlock G, Saldanha AJ, Murray Jl, Ball CA, Alexander KE, Matese JC, Perou CM, Hurt MM, Brown PO, Botstein D: Identification of genes periodically expressed in the human cell cycle and their expression in tumors. Mol Biol Cell 2002, 13:1977-2000.

8. Hanahan D, Weinberg RA: The hallmarks of cancer. Cell 2000, 100:57-70.

9. Hanahan D, Weinberg RA: Hallmarks of cancer: the next generation. Cell 2011, 144:646-674

10. Paik S, Shak S, Tang G, Kim C, Baker J, Cronin M, Baehner FL, Walker MG, Watson D, Park T, Hiller W, Fisher ER, Wickerham DL, Bryant J, Wolmark N: A multigene assay to predict recurrence of tamoxifen-treated, nodenegative breast cancer. N Engl J Med 2004, 351:2817-2826.

11. Paik S, Tang G, Shak S, Kim C, Baker J, Kim W, Cronin M, Baehner FL, Watson D, Bryant J, Costantino JP, Geyer CE Jr, Wickerham DL, Wolmark N: Gene expression and benefit of chemotherapy in women with nodenegative, estrogen receptor-positive breast cancer. J Clin Oncol 2006, 24:3726-3734

12. Sole X, Bonifaci N, Lopez-Bigas N, Berenguer A, Hernandez P, Reina O, Maxwell CA, Aguilar H, Urruticoechea A, de Sanjose S, Comellas F, Capella G, Moreno V, Pujana MA: Biological convergence of cancer signatures. PLoS One 2009, 4:e4544.

13. Venet $\mathrm{D}$, Dumont JE, Detours V: Most random gene expression signatures are significantly associated with breast cancer outcome. PLoS Comput Biol 2011, 7:e1002240.

14. Wirapati P, Sotiriou C, Kunkel S, Farmer P, Pradervand S, Haibe-Kains B, Desmedt C, Ignatiadis M, Sengstag T, Schutz F, Goldstein DR, Piccart M, Delorenzi M: Meta-analysis of gene expression profiles in breast cancer: toward a unified understanding of breast cancer subtyping and prognosis signatures. Breast Cancer Res 2008, 10:R65.

15. Alexe G, Dalgin GS, Scanfeld D, Tamayo P, Mesirov JP, DeLisi C, Harris L, Barnard N, Martel M, Levine AJ, Ganesan S, Bhanot G: High expression of lymphocyte-associated genes in node-negative HER2+ breast cancers correlates with lower recurrence rates. Cancer Res 2007, 67:10669-10676.

16. Broet P, Kuznetsov VA, Bergh J, Liu ET, Miller LD: Identifying gene expression changes in breast cancer that distinguish early and late relapse among uncured patients. Bioinformatics 2006, 22:1477-1485.
17. Rody A, Holtrich U, Pusztai L, Liedtke C, Gaetje R, Ruckhaeberle E, Solbach C, Hanker L, Ahr A, Metzler D, Engels K, Karn T, Kaufmann M: T-cell metagene predicts a favorable prognosis in estrogen receptor-negative and HER2-positive breast cancers. Breast Cancer Res 2009, 11:R15.

18. Schmidt M, Bohm D, von Torne C, Steiner E, Puhl A, Pilch H, Lehr HA, Hengstler JG, Kolbl H, Gehrmann M: The humoral immune system has a key prognostic impact in node-negative breast cancer. Cancer Res 2008, 68:5405-5413.

19. Teschendorff AE, Miremadi A, Pinder SE, Ellis IO, Caldas C: An immune response gene expression module identifies a good prognosis subtype in estrogen receptor negative breast cancer. Genome Biol 2007, 8:R157.

20. Aaltomaa S, Lipponen P, Eskelinen M, Kosma VM, Marin S, Alhava E, Syrjanen $\mathrm{K}$ : Lymphocyte infiltrates as a prognostic variable in female breast cancer. Eur J Cancer 1992, 28A:859-864.

21. Cutler SJ, Black MM, Mork T, Harvei S, Freeman C: Further observations on prognostic factors in cancer of the female breast. Cancer 1969, 24:653-667.

22. Mahmoud SM, Paish EC, Powe DG, Macmillan RD, Grainge MJ, Lee AH, Ellis IO, Green AR: Tumor-infiltrating CD8+ lymphocytes predict clinical outcome in breast cancer. J Clin Oncol 2011, 29:1949-1955.

23. Ma XJ, Salunga R, Tuggle JT, Gaudet J, Enright E, McQuary P, Payette T, Pistone M, Stecker K, Zhang BM, Zhou YX, Varnholt H, Smith B, Gadd M, Chatfield E, Kessler J, Baer TM, Erlander MG, Sgroi DC: Gene expression profiles of human breast cancer progression. Proc Natl Acad Sci USA 2003, 100:5974-5979.

24. Alizadeh AA, Eisen MB, Davis RE, Ma C, Lossos IS, Rosenwald A, Boldrick JC, Sabet H, Tran T, Yu X, Powell Jl, Yang L, Marti GE, Moore T, Hudson J Jr, Lu L, Lewis DB, Tibshirani R, Sherlock G, Chan WC, Greiner TC, Weisenburger DD, Armitage JO, Warnke R, Levy R, Wilson W, Grever MR, Byrd JC, Botstein D, Brown PO, et al: Distinct types of diffuse large B-cell lymphoma identified by gene expression profiling. Nature 2000, 403:503-511.

25. Staudt LM, Dave S: The biology of human lymphoid malignancies revealed by gene expression profiling. Adv Immunol 2005, 87:163-208.

26. Abbas AR, Baldwin D, Ma Y, Ouyang W, Gurney A, Martin F, Fong S, van Lookeren Campagne M, Godowski P, Williams PM, Chan AC, Clark HF: Immune response in silico (IRIS): immune-specific genes identified from a compendium of microarray expression data. Genes Immun 2005, 6:319-331

27. Huang da W, Sherman BT, Tan Q, Kir J, Liu D, Bryant D, Guo Y, Stephens R, Baseler MW, Lane HC, Lempicki RA: DAVID Bioinformatics Resources: expanded annotation database and novel algorithms to better extract biology from large gene lists. Nucleic Acids Res 2007, 35:W169-175.

28. Dave SS, Wright G, Tan B, Rosenwald A, Gascoyne RD, Chan WC, Fisher RI, Braziel RM, Rimsza LM, Grogan TM, Miller TP, LeBlanc M, Greiner TC, Weisenburger DD, Lynch JC, Vose J, Armitage JO, Smeland EB, Kvaloy S, Holte H, Delabie J, Connors JM, Lansdorp PM, Ouyang Q, Lister TA, Davies AJ, Norton AJ, Muller-Hermelink HK, Ott G, Campo E, et al: Prediction of survival in follicular lymphoma based on molecular features of tumor-infiltrating immune cells. N Engl I Med 2004, 351:2159-2169.

29. Buyse M, Loi S, van't Veer L, Viale G, Delorenzi M, Glas AM, d'Assignies MS, Bergh J, Lidereau R, Ellis P, Harris A, Bogaerts J, Therasse P, Floore A, Amakrane M, Piette F, Rutgers E, Sotiriou C, Cardoso F, Piccart MJ: Validation and clinical utility of a 70-gene prognostic signature for women with node-negative breast cancer. J Natl Cancer Inst 2006, 98:1183-1192.

30. Rody A, Karn T, Liedtke C, Pusztai L, Ruckhaeberle E, Hanker L, Gaetje R, Solbach C, Ahr A, Metzler D, Schmidt M, Muller V, Holtrich U, Kaufmann M: A clinically relevant gene signature in triple negative and basal-like breast cancer. Breast Cancer Res 2011, 13:R97.

31. Sorlie T, Perou CM, Tibshirani R, Aas T, Geisler S, Johnsen H, Hastie T, Eisen MB, van de Rijn M, Jeffrey SS, Thorsen T, Quist H, Matese JC, Brown PO, Botstein D, Eystein Lonning P, Borresen-Dale AL: Gene expression patterns of breast carcinomas distinguish tumor subclasses with clinical implications. Proc Natl Acad Sci USA 2001, 98:10869-10874.

32. Bianchini G, Qi Y, Alvarez RH, Iwamoto T, Coutant C, Ibrahim NK, Valero V, Cristofanilli M, Green MC, Radvanyi L, Hatzis C, Hortobagyi GN, Andre F, Gianni L, Symmans WF, Pusztai L: Molecular anatomy of breast cancer stroma and its prognostic value in estrogen receptor-positive and -negative cancers. J Clin Oncol 2010, 28:4316-4323. 
33. Teschendorff AE, Gomez S, Arenas A, El-Ashry D, Schmidt M, Gehrmann M Caldas C: Improved prognostic classification of breast cancer defined by antagonistic activation patterns of immune response pathway modules. BMC Cancer 2010, 10:604.

34. Perou CM: Molecular stratification of triple-negative breast cancers. Oncologist 2010, 16(Suppl 1):61-70.

35. Prat A, Parker JS, Karginova O, Fan C, Livasy C, Herschkowitz J, He X, Perou CM: Phenotypic and molecular characterization of the claudin-low intrinsic subtype of breast cancer. Breast Cancer Res 2010, 12:R68.

36. Fridman WH, Pages F, Sautes-Fridman C, Galon J: The immune contexture in human tumours: impact on clinical outcome. Nat Rev Cancer 2011, 12:298-306

37. Galon J, Fridman WH, Pages F: The adaptive immunologic microenvironment in colorectal cancer: a novel perspective. Cancer Res 2007, 67:1883-1886.

38. Clemente CG, Mihm MC Jr, Bufalino R, Zurrida S, Collini P, Cascinelli N Prognostic value of tumor infiltrating lymphocytes in the vertical growth phase of primary cutaneous melanoma. Cancer 1996, 77:1303-1310.

39. Tefany FJ, Barnetson RS, Halliday GM, McCarthy SW, McCarthy WH: Immunocytochemical analysis of the cellular infiltrate in primary regressing and non-regressing malignant melanoma. J Invest Dermatol 1991, 97:197-202.

40. Sato E, Olson SH, Ahn J, Bundy B, Nishikawa H, Qian F, Jungbluth AA, Frosina D, Gnjatic S, Ambrosone C, Kepner J, Odunsi T, Ritter G, Lele S, Chen YT, Ohtani H, Old LJ, Odunsi K: Intraepithelial CD8+ tumorinfiltrating lymphocytes and a high $\mathrm{CD} 8+$ /regulatory $\mathrm{T}$ cell ratio are associated with favorable prognosis in ovarian cancer. Proc Natl Acad Sci USA 2005, 102:18538-18543.

41. Zhang L, Conejo-Garcia JR, Katsaros D, Gimotty PA, Massobrio M, Regnani G, Makrigiannakis A, Gray H, Schlienger K, Liebman MN, Rubin SC, Coukos G: Intratumoral T cells, recurrence, and survival in epithelial ovarian cancer. N Engl J Med 2003, 348:203-213.

42. Baier PK, Wimmenauer S, Hirsch T, von Specht BU, von Kleist S, Keller H, Farthmann EH: Analysis of the T cell receptor variability of tumorinfiltrating lymphocytes in colorectal carcinomas. Tumour Biol 1998, 19:205-212.

43. Galon J, Costes A, Sanchez-Cabo F, Kirilovsky A, Mlecnik B, Lagorce-Pages C, Tosolini M, Camus M, Berger A, Wind P, Zinzindohoue F, Bruneval P Cugnenc PH, Trajanoski Z, Fridman WH, Pages F: Type, density, and location of immune cells within human colorectal tumors predict clinical outcome. Science 2006, 313:1960-1964.

44. Galon J, Pages F, Marincola FM, Angell HK, Thurin M, Lugli A, Zlobec I, Berger A, Bifulco C, Botti G, Tatangelo F, Britten CM, Kreiter S, Chouchane L, Delrio P, Arndt H, Asslaber M, Maio M, Masucci GV, Mihm M, VidalVanaclocha F, Allison JP, Gnjatic S, Hakansson L, Huber C, Singh-Jasuja H, Ottensmeier C, Zwierzina H, Laghi L, Grizzi F, et al: Cancer classification using the Immunoscore: a worldwide task force. J Transl Med 2012, 10:205.

45. Pages F, Berger A, Camus M, Sanchez-Cabo F, Costes A, Molidor R, Mlecnik B, Kirilovsky A, Nilsson M, Damotte D, Meatchi T, Bruneval P, Cugnenc PH, Trajanoski Z, Fridman WH, Galon J: Effector memory T cells, early metastasis, and survival in colorectal cancer. N Engl J Med 2005, 353:2654-2666.

46. Reiman JM, Kmieciak M, Manjili MH, Knutson KL: Tumor immunoediting and immunosculpting pathways to cancer progression. Semin Cancer Biol 2007, 17:275-287.

47. Shankaran V, Ikeda H, Bruce AT, White JM, Swanson PE, Old LJ, Schreiber RD: IFNgamma and lymphocytes prevent primary tumour development and shape tumour immunogenicity. Nature 2001, 410:1107-1111.

48. van den Broek ME, Kagi D, Ossendorp F, Toes R, Vamvakas S, Lutz WK Melief CJ, Zinkernagel RM, Hengartner $\mathrm{H}$ : Decreased tumor surveillance in perforin-deficient mice. J Exp Med 1996, 184:1781-1790.

49. Carlomagno C, Perrone F, Lauria R, de Laurentiis M, Gallo C, Morabito A, Pettinato G, Panico L, Bellelli T, Apicella A: Prognostic significance of necrosis, elastosis, fibrosis and inflammatory cell reaction in operable breast cancer. Oncology 1995, 52:272-277.

50. Holmberg L, Adami HO, Lindgren A, Ekbom A, Sandstrom A, Bergstrom R: Prognostic significance of the Ackerman classification and other histopathological characteristics in breast cancer. An analysis of 1,349 consecutive cases with complete follow-up over seven years. APMIS 1988, 96:979-990.

51. Lee AH, Gillett CE, Ryder K, Fentiman IS, Miles DW, Millis RR: Different patterns of inflammation and prognosis in invasive carcinoma of the breast. Histopathology 2006, 48:692-701.

52. Pupa SM, Bufalino R, Invernizzi AM, Andreola S, Rilke F, Lombardi L, Colnaghi MI, Menard S: Macrophage infiltrate and prognosis in c-erbB-2overexpressing breast carcinomas. J Clin Oncol 1996, 14:85-94.

53. Elston CW, Gresham GA, Rao GS, Zebro T, Haybittle JL, Houghton J, Kearney G: The cancer research campaign (King's/Cambridge) trial for early breast cancer: clinico-pathological aspects. Br J Cancer 1982, 45:655-669.

54. Menard S, Casalini P, Tomasic G, Pilotti S, Cascinelli N, Bufalino R, Perrone F, Longhi C, Rilke F, Colnaghi Ml: Pathobiologic identification of two distinct breast carcinoma subsets with diverging clinical behaviors. Breast Cancer Res Treat 1999, 55:169-177.

55. Desmedt C, Haibe-Kains B, Wirapati P, Buyse M, Larsimont D, Bontempi G, Delorenzi M, Piccart M, Sotiriou C: Biological processes associated with breast cancer clinical outcome depend on the molecular subtypes. Clin Cancer Res 2008, 14:5158-5165.

56. Teschendorff $A E$, Caldas $C$ : A robust classifier of high predictive value to identify good prognosis patients in ER-negative breast cancer. Breast Cancer Res 2008, 10:R73.

57. Kreike $B$, van Kouwenhove $M$, Horlings $H$, Weigelt $B$, Peterse $H$, Bartelink $H$, van de Vijver MJ: Gene expression profiling and histopathological characterization of triple-negative/basal-like breast carcinomas. Breast Cancer Res 2007, 9:R65.

58. Bai M, Agnantis NJ, Kamina S, Demou A, Zagorianakou P, Katsaraki A, Kanavaros $P$ : In vivo cell kinetics in breast carcinogenesis. Breast Cancer Res 2001, 3:276-283.

59. Lee JS, Kim HS, Jung JJ, Kim YB, Park CS, Lee MC: Correlation between angiogenesis, apoptosis and cell proliferation in invasive ductal carcinoma of the breast and their relation to tumor behavior. Anal Quant Cytol Histol 2001, 23:161-168.

60. Lipponen P: Apoptosis in breast cancer: relationship with other pathological parameters. Endocr Relat Cancer 1999, 6:13-16.

61. Schulte-Hermann R, Bursch W, Grasl-Kraupp B, Marian B, Torok L, KahlRainer $P$, Ellinger A: Concepts of cell death and application to carcinogenesis. Toxicol Pathol 1997, 25:89-93.

62. Kono H, Rock KL: How dying cells alert the immune system to danger. Nat Rev Immunol 2008, 8:279-289.

63. Nowak AK, Lake RA, Marzo AL, Scott B, Heath WR, Collins EJ, Frelinger JA, Robinson BW: Induction of tumor cell apoptosis in vivo increases tumor antigen cross-presentation, cross-priming rather than cross-tolerizing host tumor-specific CD8 T cells. J Immunol 2003, 170:4905-4913.

64. Rock KL, Lai JJ, Kono H: Innate and adaptive immune responses to cell death. Immunol Rev 2011, 243:191-205.

65. Martinet L, Garrido I, Filleron T, Le Guellec S, Bellard E, Fournie JJ, Rochaix P, Girard JP: Human solid tumors contain high endothelial venules: association with T- and B-lymphocyte infiltration and favorable prognosis in breast cancer. Cancer Res 2011, 71:5678-5687.

66. Liu F, Lang R, Zhao J, Zhang X, Pringle GA, Fan Y, Yin D, Gu F, Yao Z, Fu L: CD8(+) cytotoxic $T$ cell and FOXP3(+) regulatory $T$ cell infiltration in relation to breast cancer survival and molecular subtypes. Breast Cancer Res Treat 2011, 130:645-655.

67. Mahmoud SM, Paish EC, Powe DG, Macmillan RD, Lee AH, Ellis IO, Green AR: An evaluation of the clinical significance of FOXP3+ infiltrating cells in human breast cancer. Breast Cancer Res Treat 2011, 127:99-108.

68. Nakamura R, Sakakibara M, Nagashima T, Sangai T, Arai M, Fujimori T, Takano S, Shida T, Nakatani Y, Miyazaki M: Accumulation of regulatory T cells in sentinel lymph nodes is a prognostic predictor in patients with node-negative breast cancer. Eur J Cancer 2009, 45:2123-2131.

69. Yan M, Jene N, Byrne D, Millar EK, O'Toole SA, McNeil CM, Bates GJ, Harris AL, Banham AH, Sutherland RL, Fox SB: Recruitment of regulatory $T$ cells is correlated with hypoxia-induced CXCR4 expression, and is associated with poor prognosis in basal-like breast cancers. Breast Cancer Res 2011, 13:R47

70. Carr JM, Carrasco MJ, Thaventhiran JE, Bambrough PJ, Kraman M, Edwards AD, Al-Shamkhani A, Fearon DT: CD27 mediates interleukin-2- 
independent clonal expansion of the CD8+ T cell without effector differentiation. Proc Natl Acad Sci USA 2006, 103:19454-19459.

71. Hendriks J, Gravestein LA, Tesselaar K, van Lier RA, Schumacher TN, Borst J: CD27 is required for generation and long-term maintenance of $T$ cell immunity. Nat Immunol 2000, 1:433-440.

72. Agematsu K, Hokibara S, Nagumo H, Shinozaki K, Yamada S, Komiyama A: Plasma cell generation from B-lymphocytes via CD27/CD70 interaction. Leuk Lymphoma 1999, 35:219-225.

73. Agematsu K, Nagumo H, Yang FC, Nakazawa T, Fukushima K, Ito S, Sugita K Mori T, Kobata T, Morimoto C, Komiyama A: B cell subpopulations separated by $\mathrm{CD} 27$ and crucial collaboration of $\mathrm{CD} 27+\mathrm{B}$ cells and helper T cells in immunoglobulin production. Eur J Immunol 1997, 27:2073-2079.

74. Hayakawa Y, Smyth MJ: CD27 dissects mature NK cells into two subsets with distinct responsiveness and migratory capacity. J Immunol 2006, 176:1517-1524.

75. Chan OT, Yang LX: The immunological effects of taxanes. Cancer Immunol Immunother 2000, 49:181-185.

76. Haynes NM, van der Most RG, Lake RA, Smyth MJ: Immunogenic anticancer chemotherapy as an emerging concept. Curr Opin Immunol 2008, 20:545-557.

77. Mattarollo SR, Loi S, Duret H, Ma Y, Zitvogel L, Smyth MJ: Pivotal role of innate and adaptive immunity in anthracycline chemotherapy of established tumors. Cancer Res 2011, 71:4809-4820.

78. Tsavaris N, Kosmas C, Vadiaka M, Kanelopoulos P, Boulamatsis D: Immune changes in patients with advanced breast cancer undergoing chemotherapy with taxanes. Br J Cancer 2002, 87:21-27.

79. Edgar R, Domrachev M, Lash AE: Gene Expression Omnibus: NCBI gene expression and hybridization array data repository. Nucleic Acids Res 2002, 30:207-210.

80. Gene Expression Omnibus.. [http://ncbi.nlm.nih.gov/geo/query/acc.cgi? acc=GSE45255].

81. R Development Core Team: R: A Language and Environment for Statistical Computing. R Foundation for Statistical Computing. Vienna, Austria 2010.

82. , Bioconductor [http://www.bioconductor.org/packages/2.12/bioc/html/ simpleaffy.html].

83. Johnson WE, Li C, Rabinovic A: Adjusting batch effects in microarray expression data using empirical Bayes methods. Biostatistics 2007, 8:118-127.

84. Hu Z, Fan C, Oh DS, Marron JS, He X, Qaqish BF, Livasy C, Carey LA, Reynolds E, Dressler L, Nobel A, Parker J, Ewend MG, Sawyer LR, Wu J, Liu Y, Nanda R, Tretiakova M, Ruiz Orrico A, Dreher D, Palazzo JP, Perreard L, Nelson E, Mone M, Hansen H, Mullins M, Quackenbush JF, Ellis MJ, Olopade Ol, Bernard PS, et al: The molecular portraits of breast tumors are conserved across microarray platforms. BMC Genomics 2006, 7:96.

85. Fan C, Oh DS, Wessels L, Weigelt B, Nuyten DS, Nobel AB, van't Veer $L$, Perou CM: Concordance among gene-expression-based predictors for breast cancer. N Engl J Med 2006, 355:560-569.

86. UNC Microarray database.. [https://genome.unc.edu/pubsup/breastGEO].

87. Normand ST, Landrum MB, Guadagnoli E, Ayanian JZ, Ryan TJ, Cleary PD, McNeil BJ: Validating recommendations for coronary angiography following acute myocardial infarction in the elderly: a matched analysis using propensity scores. J Clin Epidemiol 2001, 54:387-398.

88. Therneau T: Survival: survival analysis, including penalized likelihood. $R$ package (version 2.36-5) Vienna, Austria: R Foundation for Statistical Computing; 2011.

89. Benjamini $Y$, Hochberg $Y$ : Controlling the false discovery rate - a practical and powerful approach to multiple testing. Journal of the Royal Statistical Society Series B-Methodological 1995, 57:289-300.

90. Eisen Lab Software.. [http://rana.lbl.gov/EisenSoftware.htm]

91. Eisen MB, Spellman PT, Brown PO, Botstein D: Cluster analysis and display of genome-wide expression patterns. Proc Natl Acad Sci USA 1998, 95:14863-14868.

92. Park MY, Hastie T, Tibshirani R: Averaged gene expressions for regression. Biostatistics 2007, 8:212-227

93. Lash $\mathrm{TL}$, Cronin-Fenton D, Ahern TP, Rosenberg $\mathrm{CL}$, Lunetta $\mathrm{KL}$, Silliman $\mathrm{RA}$, Garne JP, Sorensen HT, Hellberg Y, Christensen M, Pedersen L, HamiltonDutoit S: CYP2D6 inhibition and breast cancer recurrence in a population-based study in Denmark. J Natl Cancer Inst 2011, 103:489-500.
94. Cronin-Fenton DP, Hellberg Y, Lauridsen KL, Ahern TP, Garne JP, Rosenberg C, Silliman RA, Sorensen HT, Lash TL, Hamilton-Dutoit S: Factors associated with concordant estrogen receptor expression at diagnosis and centralized re-assay in a Danish population-based breast cancer study. Acta Oncol 2012, 51:254-261.

95. Huang da W, Sherman BT, Lempicki RA: Systematic and integrative analysis of large gene lists using DAVID bioinformatics resources. Nat Protoc 2009, 4:44-57.

96. DAVID.. [http://david.abcc.ncifcrf.gov/].

97. Desmedt C, Piette F, Loi S, Wang Y, Lallemand F, Haibe-Kains B, Viale G, Delorenzi M, Zhang Y, d'Assignies MS, Bergh J, Lidereau R, Ellis P, Harris AL, Klijn JG, Foekens JA, Cardoso F, Piccart MJ, Buyse M, Sotiriou C: Strong time dependence of the 76-gene prognostic signature for node-negative breast cancer patients in the TRANSBIG multicenter independent validation series. Clin Cancer Res 2007, 13:3207-3214.

doi:10.1186/gb-2013-14-4-r34

Cite this article as: Nagalla et al: Interactions between immunity, proliferation and molecular subtype in breast cancer prognosis. Genome Biology 2013 14:R34.

\section{Submit your next manuscript to BioMed Central and take full advantage of:}

- Convenient online submission

- Thorough peer review

- No space constraints or color figure charges

- Immediate publication on acceptance

- Inclusion in PubMed, CAS, Scopus and Google Scholar

- Research which is freely available for redistribution

Submit your manuscript at www.biomedcentral.com/submit
Biomed Central 